\title{
AGGREGATION BIAS IN ELASTICITIES OF SUBSTITUTION AND THE MINIMUM WAGE PARADOX
}

\author{
Coen N. TEULINGS \\ Department of Economics \\ University of Amsterdam \\ Roetersstraat 11 \\ 1018 WB AMSTERDAM
}

August 1998

\begin{abstract}
$\underline{\text { Abstract }}$
While the employment effects of minimum wages are usually reported to be small (suggesting low substitutability between skill types), direct estimates suggest a much larger degree of substitutability. This paper argues that this paradox is largely due to a bias induced by the aggregation of skill types into broad categories. An assignment model is applied where skilled workers have a comparative advantage in complex jobs. The implied pattern of substitutability reveals the sources of the bias. Estimation results for the United States show elasticities of complementarity to be underestimated by up to a factor 2.5. The methods laid out can likewise be applied to other markets where different quality types are close substitutes, like the housing market.
\end{abstract}

keywords: aggregation bias, assignment models, substitution, minimum wages

The author thanks Reiniera Doude for computational assistance, Dan Feenberg and Thomas Lemieux for providing a guide to the use of CPS data, Risto Heymans for his statistical advice, and Dan Hamermesh, Thomas Piketty, and the participants of a NBER labor seminar for their comments. 


\section{Introduction}

There is a large body of literature on the employment effects of minimum wages. No matter whether one refers to the research on the seventies, reviewed extensively in Brown, Gillroy and Kohen (1982), or to the more controversial evidence on the nineties collected by Card and Krueger (1995), the general conclusion is that minimum wages have at best a limited impact on employment. On the other hand, the plots presented in DiNardo, Fortin and Lemieux (1996) and more recent evidence by Lee (1998) and Teulings (1998) suggest that reduction of real minimum wages contributed substantially to the rise in wage inequality in the eighties. For labor economists, these conclusions should be puzzling. Most of our estimates suggest elasticities of complementarity to be small, see Topel (1994) or see Hamermesh (1993) for an overview: changes in the supply of a skill type have only a restricted impact on wages for other skill types. However, the limited employment effect of minimum wages the large effects on relative wages can only be reconciled within a standard equilibrium model of the labor market when elasticities of complementarity are large (in absolute value). An increase in the minimum wage would then produce a slight reduction in low-skilled employment and, as a result of it, a large wage increase for the low-skilled workers who remain employed. Let us refer to this inconsistency in our present understanding of labor demand as the minimum wage paradox.

The main thesis of this paper is that this paradox is due to the aggregation of workers in broader skill groups. If types of labor were properly disaggregated, our estimates of elasticities of complementarity would be much larger, in some cases even up to a factor 2.5. My approach is not to classify workers in skill groups at all, but to use a continuous classification with an infinite number of skill categories. The basic idea of this approach has been set out previously in Teulings (1995a). There, I analyzed a model where both workers and jobs differ along a single dimension: workers are attributed some level of skill and jobs some level of complexity. Both the level of skill and of complexity vary continuously on (some subset of) the real domain. The labor market allots worker types 
to job types. Each job type produces a commodity that is traded on commodity markets. Hence, there are two types of substitution in this model, within-job-between-worker substitution on the labor market and between-job substitution on the commodity market. Types of workers are assumed to be perfect substitutes within a job type. However, because highly skilled workers have a comparative advantage in complex jobs, workers are not perfect substitutes across jobs. In this world, workers are allotted to job types according to their skill level, the most highly skilled worker to the most complex job. Substitution is driven by the spill-over effects of excess supplies and demands from neighboring markets, for example, all workers moving to a somewhat less complex job in order to create vacancies in the most complex jobs for a bunch of Harvard graduates entering the market.

The notion that this type of model is a good instrument for analyzing the substitutability of worker types is present already in Teulings (1995a). However, the issue is not addressed explicitly there. One of the problems is the assumption of perfect substitution of worker types within a job type. Elasticities of substitution and complementarity are derived from the second derivative of the cost and production functions for the economy as a whole. With perfect substitution, the cost function for a job type is not differentiable, since iso-cost curves are kinked. This problem is resolved in this paper by introducing slight imperfections in the degree of substitutability within a job type. Perfect substitution is viewed as the limiting case.

This approach to deriving elasticities of substitution and complementarity produces a number of intuitively appealing results. The elasticities of substitution exhibit the distance-dependent elasticity of substitution (DIDES) structure: the larger the distance in terms of skill between two worker types, the smaller will be the elasticity of substitution. These elasticities are used to calculate the elasticities of complementarity by matrix inversion. The elasticities of complementarity will peak sharply (in absolute value) at the own type. This peak yields the large aggregation bias, since it will be smoothed out when estimation is based on broad skill categories.

A practical advantage of the assumption of perfect within-job substitution is that it yields 
a one-to-one correspondence between skills and complexities: each skill type is employed in single job type and vice versa. The economic rationale for this result is that with perfect substitution within a job type, the productivity of each worker type is independent of the number of workers of other types employed in that job type. Employers will therefore hire only the worker type with the lowest cost per efficiency unit of labor. As long as this cost curve has a global minimum, ${ }^{1}$ the one-to-one correspondence applies. With imperfect substitution, this result breaks down: several types of workers will be employed in a single job type. By hiring more workers of the one type, the (marginal) productivity of other types of workers will rise. Hence, employers will hire workers of all types, each in such a ratio that its marginal productivity is equal to its wage. Market equilibrium will therefore be described by a simultaneous distribution of skills and complexities.

As a reminder for the reader, the paper starts with a short discussion of the model with perfect within-job-between-worker substitution in Section 2. Section 3 develops the general model with imperfect substitution. In Section 4, the elasticities of substitution and complementarity are derived. The empirical application of these analytical results requires estimates of the main parameters of the model. Section 5 discusses the estimation procedure and its main results. Estimation refers to the United States economy for 4 years (1973, 1979, 1985 and 1990), viewing the four major regions as separate economies. Since the procedure is basically the same as in Teulings (1995a), the discussion is confined to the main lines. Section 6 puts my ideas to the test. The elasticities of complementarity estimated on the basis of DIDES/comparative advantage model are comparable to previous estimates, for example those by Altonji and Card (1991) based on the influx of migrants or the economy-wide estimates by Topel (1994). The analysis reveals a large aggregation bias. The surplus value of the model comes to the surface most clearly in an analysis of the effects of the decline in the real minimum wage between 1979 and 1990. The minimum wage paradox is largely resolved. A counterfactual

${ }^{1}$ This requires the absense of mass points in the distribution of product demand, see Teulings (1995a). 
calculation for 1990 where the minimum wage for 1979 applies reveals that most of the increase in wage inequality can be explained by the decline in the minimum. Section 7 concludes.

\section{The model with perfect within-job substitution}

Four assumptions are crucial for the model with perfect within-job substitution:

i) single dimensionality for workers: workers can be classified by a single index referred to as the skill; let $s$ denote this skill index: $s$ can take any real value;

ii) single dimensionality for jobs: like workers, jobs can be classified by a single index referred to as job complexity; let $c$ denote job complexity; $c$ can take any positive value;

iii) absolute advantage: let $\exp [g(s, c)]$ denote the productivity of worker type $s$ in job type $c$; better skilled workers will be more productive than less skilled, irrespective of job complexity: $g_{s}(s, c)>0$;

iv) comparative advantage: better skilled workers have a comparative advantage in complex jobs; their productivity ratio increases with complexity: $g_{s c}(s, c)>0$.

Types of labor are traded on labor markets. Each job type produces a commodity that is traded on commodity markets. Firms maximize profits. For the sake of simplicity, each firm is assumed to offer jobs at a single level of complexity. ${ }^{2}$ All markets are perfectly competitive. Hence, firms face a zero profit constraint. The amount of leisure and job characteristics do not enter into the utility function of the worker. Hence, workers simply maximize their income from a fixed supply of labor and wages do not incorporate compensating differentials. The specification above implies perfect substitution of worker types within a job type; if not, the (marginal) productivity of type $s$ in job type $c$ would be dependent on the number of workers of other skill types employed in that job type.

\footnotetext{
${ }^{2}$ This assumption is simply a matter of the presentation of the model. Nothing would change in the equations if the assumption were relaxed.
} 
A convenient specification of the function $g(s, c)$ is: $g(s, c)=s c$. This specification is flexible. Since the scales of measurement of $s$ and $c$ have not yet been defined, it covers the whole class of functions that is multiplicatively separable, $g(s, c)=g^{1}(s) g^{2}(c)$, by a suitable transform of $s$ and $c$. Let $w(s)$ denote the log market wage of type $s$. A firm offering of a job of complexity $c$ will minimize its cost per efficiency unit of labor, exp[ $w(s)-g(s, c)]$. The first-order condition is:

$w^{\prime}(s)=c$.

Since $c>0$ by assumption, $w^{\prime}(s)>0$. This is the consequence of absolute advantage. Higher $s$-types are more productive in any job type, so they will earn higher wages. This first-order condition establishes a correspondence between the job type $c$ to which a particular $s$ type is allotted in a particular economy and the return to skill $w^{\prime}(s)$ in that economy. This correspondence will be the starting point for estimation, in particular for the identification of the scale of measurement of $s$ and $c$.

Let $c(s)$ denote the complexity $c$ of the firm employing type $s$ workers in market equilibrium. Since the first-order condition applies for all $s$, substitution of $c$ by $c(s)$ in the first order condition and differentiation with respect to $s$ yields:

$w^{\prime \prime}(s)=c^{\prime}(s)>0$.

where the inequality is due to the second-order condition of the firm. That $c^{\prime}(s)$ is positive is the consequence of comparative advantage: better skilled workers are allotted to more complex jobs.

The situation is depicted in graph form in Figure 1. The firm chooses its optimal worker type $s$ such that the relative cost of hiring an additional unit of skill, $w^{\prime}(s)$, is equal to the relative productivity gain $c$. The second-order condition requires the relative cost of hiring even better skilled workers to be increasing. Figure 1 reveals the optimal skill type for a more complex job (a higher $c$ ) to be higher.

Figure 1 gives an intuition for a result which will turn out to be crucial: the degree of economy-wide substitutability between worker types is inversely related to $w^{\prime \prime}(s)$. The higher $w^{\prime \prime}(s)$, the more curved is the wage function at the point of tangency. By the equality $w^{\prime \prime}(s)=c^{\prime}(s), w^{\prime \prime}(s)$ can be interpreted as a measure of the dispersion of job 
complexity: the greater $w^{\prime \prime}(s)$, the greater the job heterogeneity. The greater the job heterogeneity, the more limited will be the scope for substitution. In the extreme case, $w^{\prime \prime}(s)=0$, all jobs have the same complexity and worker types will be perfectly substitutable by the assumption of perfect within-job substitution.

Whether or not there is imperfect within-job substitution is largely an issue of the coarseness of the classification of jobs. To see this, consider the following thought experiment. Let the imperfection in the substitution be due to the fact that an employer wants to have both experienced and inexperienced workers doing a particular job, so that the experienced workers can transfer their skills to the inexperienced workers. This imperfection in the degree of substitution would be resolved by defining the transfer of skills as a separate job type. Hence, a model with perfect within-job substitution is fully consistent with both economic theory and our empirical knowledge, in particular when we allow for an infinite number of job types, as we do here. The only reason for considering the model with imperfect substitution is that it enables the calculation of economy-wide elasticities of substitution and complementarity.

\section{The model with imperfect within-job substitution}

\subsection{Assumptions}

On top of the assumptions discussed in Section 2, the model with imperfect within-job substitution requires some additional notation and assumptions. Without loss of generality, total labor supply is normalized to unity. The logarithm of the density function of $s$, representing its distribution among labor supply, is denoted as $e(s)$. It is exogenous by the above assumptions. $e($.$) is assumed to be twice differentiable. Furthermore, it is assumed$ that $e^{\prime \prime}()<$.0 . This is a very weak assumption, which is satisfied for almost all standard distributions. ${ }^{3}$

${ }^{3}$ Weak instead of strict negativity applies only for the exponential and the uniform distribution. Furthermore, for the limiting case of perfect within-job-between-skill- 
By the definition of $\exp [f()$.$] as a density we have:$

$\int_{0}^{\infty} L_{-\infty}^{\infty} \exp [f(s, c)] \mathrm{d} s \mathrm{~d} c=1$.

$e($.$) is related to f($.$) by:$

$e(s)=\ln \left[r_{0}^{\infty} \exp [f(s, c)] \mathrm{d} c\right]$.

For future reference, when $f(s, c)$ is twice differentiable, the first two derivatives of $e(s)$ are given by:

$$
\begin{aligned}
& e^{\prime}(s)=\mathrm{E}_{\mathrm{f}} f_{s}(s, c) \mid s_{]} \\
& e^{\prime \prime}(s)=\mathrm{E}_{[} f_{s s}(s, c)\left|s_{]}+\mathrm{V}_{\mathrm{f}} f_{s}(s, c)\right| s_{]}
\end{aligned}
$$

where $\mathrm{E}[$.$] and \mathrm{V}[$.$] denote the expectation and the variance operator and where$ subscripts refer to the relevant partial derivatives. Because $e "()<$.0 by assumption and a variance is always positive: $\mathrm{E}\left[f_{s s}(s, c)^{*} s\right]<0$.

The output of a firm offering jobs of complexity $c$ is governed by a CES production function for a continuously changing pattern of factors of production: ${ }^{4}$

type substitution, the assumption is superfluous.

${ }^{4}$ MacDonald (1982) was the first to use the concept of a CES production function with an infinite number of inputs. He considered the problem of a firm that has to allot its workforce, made up of two types of workers, to an infinite number of 'tasks' (the equivalent of 'jobs' in this paper) which together produce a single output. The contribution of each task to output is governed by this CES function, analogous to equation (3) below.

The present model generalizes Macdonald's model in two respects. First, it considers an infinite number of worker types instead of just two. Secondly, the elasticity of substitution between worker types is infinite in Macdonald's model, while it can take any value in the present model: see equation (2) where the same type of CES function is applied, but now to the relation between the inputs of worker types and the output of a job type. 


$$
\left.\frac{\delta-1}{o} y(c)=\ln \left[\int_{-\infty}^{\infty} \exp g(s, c)+\frac{\sigma^{-}-1}{\sigma} f(s, c)\right] d s\right]
$$

where:

$f(s, c)=\quad$ the logarithm of the joint density function of worker type $s$ and job type $c$, its shape will be determined endogenously;

$g(s, c)=\quad$ a function representing the technology for the production in job type $c$;

$y(c)=$ the logarithm of the output of job type $c$;

ó $\quad=\quad$ the within-job-between-skill elasticity of substitution; ó $>1$.

The specification implies that production technology is characterized by constant returns to scale. As in Section 2, $g($.$) is specified as:$

$g(s, c)=s c$.

In the model with imperfect substitution, however, the interpretation of $g($.$) as$ representing the productivity of type $s$ in job $c$ is less adequate, as the (marginal) productivity of each worker type depends on the share of all other worker types in production.

Consumption is the only purpose of production. The utility functions of all consumers are identical and homothetic. The demand for products of various complexity depends therefore only on total income, not on its distribution. The utility function reads as:

$$
\left.\frac{\mathrm{c}-1}{\mathrm{c}} x=\ln \left[\int_{0}^{\infty} \exp h(c)+\frac{\mathrm{c}-1}{\mathrm{c}} y(c)\right] d c\right]
$$

where:

$x=$ the logarithm of total consumption;

$h(c)=$ a differentiable function measuring the preference of consumers for product type $c$;

ç $=$ the between-job elasticity of substitution, $c ̧ \geq 0$. 


\subsection{Market equilibrium}

Competition equates the wage rates for identical workers across job types. A firm of type $c$ chooses the optimal skill composition of its work force by maximizing its output subject to its wage bill and to the market wages for each skill type. This is an iso-perimetric problem (see MacDonald 1982). Adding up for all $c$-type firms, the solution reads:

$$
f(s, c)=o ́[s c-w(s)+p(c)]+y(c)
$$

where:

$w(s) \quad=\quad$ the logarithm of the equilibrium wage for type $s$;

$p(c)=$ the logarithm of the price of products of job type $c$.

Equation (4) is a standard CES demand function. An increase of $w(s)$ by one percent would reduce labor demand by $c$-type firms for skill type $s$ by ó percent. $w(s), p(c), f(s, c)$ and $y(c)$ can be shown to be differentiable in market equilibrium.

Equation (4) holds identically for all $s$. Differentiating (4) with respect to $s$, taking the expectation with respect to $c$ and applying equation (1) yields:

$$
w^{\prime}(s)=c(s)-\frac{1}{o} e^{\prime}(s)
$$

where:

$c(s) \equiv \mathrm{E}\left[c^{*} s\right]$.

Equation (5) is central to the estimation of the model, as it postulates a relation between job complexity and the return to skill. In the special case ó $=\infty$, equation (5) reduces to: $w^{\prime}(s)=c(s)$. This is the model of Section 2. $c(s)$ measures the relative scarcity of skill: the higher $c(s)$ for a given $s$, the more scarce is skill. When the supply of highly skilled workers decreases, an average skill type ends up in a more complex job. The other way around, when the demand in highly complex job types goes up, the same average skill type will also end up in a more complex job. In both cases, the return to skill goes up. 
Testing whether ó $=\infty$ or ó is finite can be done by a simple exclusion restriction of $e^{\prime}(s) .^{5}$ Such tests are reported in Teulings (1995b); perfect substitution could not be rejected. By differentiating equation (4) with respect to $s$ twice we get:

$f_{s s}(s, c)=-$ ó $w^{\prime \prime}(s)$.

$f_{s s}(s, c)$ does not depend on $c$ and is therefore equal to its expectation. By equation (1) and by the assumption that $e^{\prime \prime}(s)<0$ we have: $w^{\prime \prime}(s)>0$.

The demand for products of various complexity follows again from solving an isoperimetric problem, analogous to equation (4). Its solution yields a CES demand function for the products of job type $c$ :

$$
y(c)=c_{\zeta}\left[h(c)+p_{x}-p(c)\right]+x
$$

where:

$p_{x}=$ the logarithm of the price of a unit of consumption. ${ }^{6}$

\section{Elasticities of substitution and complementarity}

\subsection{General approach}

Elasticities of substitution measure the effect of increasing the price of one input on the demand for other inputs. They can be most easily derived from the first derivative of the

${ }^{5}$ Some discussants suggested that $c(s)$ is analogous to a demand shifter and $e^{\prime}(s)$ to a supply shifter, as in the standard approach of e.g. Katz and Murphy (1992), and hence that both should be included. This interpretation is mistaken. $c(s)$ is affected by both supply and demand shifts. The best way to see the difference is to note that $c(s)$ measures the type of job, where the usual demand shifters measure the number of jobs. There is therefore a difference in dimension.

${ }^{6} p_{x}$ can either be interpreted as the price of a composite commodity composed of all $c$-types or as the price deflator of income. The choice between both interpretations has no implications for the subsequent results. 
cost function: $\underline{\mathrm{C}}_{\mathrm{P}}[\underline{\mathrm{P}}] \equiv \underline{\mathrm{X}}[\underline{\mathrm{P}}]$, where $C[\underline{\mathrm{P}}]$ is the cost as a function of a vector of input prices $\underline{P}$ (vectors will be underlined) per unit of output ${ }^{7}$, where $\underline{C}_{P}[\underline{P}]$ is the vector of first derivatives, and where $\underline{X}[\underline{P}]$ denotes the vector of input demands. The second derivatives give the effect of price increases on input demands: $\mathrm{d} \underline{X}[\underline{\mathrm{P}}] / \mathrm{d} \underline{P^{\prime}}=\mathbf{C}_{\mathrm{PP}^{\prime}}$ (bolds denote matrices). The elasticities of substitution can be derived from this matrix by a straightforward normalization.

Elasticities of complementarity, on the other hand, measure the effect of increasing the supply of one input on the prices of all other inputs. These can be most easily derived from the production function: $\underline{\mathrm{F}}_{\mathrm{X}}[\underline{\mathrm{X}}] \equiv \underline{\mathrm{P}}[\underline{\mathrm{X}}]$, where $F[\underline{\mathrm{X}}]$ is the production function and $\underline{P}[\underline{X}]$ the vector of input prices. Taking the second derivative yields the effect of supply increases on input prices: $\mathrm{d} \underline{\mathrm{P}}[\underline{\mathrm{X}}] / \mathrm{d} \underline{\mathrm{X}}^{\prime}=\mathbf{F}_{\mathrm{XX}}$.

Getting from elasticities of substitution to elasticities of complementarity requires therefore matrix inversion, which can be quite cumbersome for large matrices. However, in our case, the economy-wide cost function can be derived easily, but not the production function. If we are interested in the elasticities of complementarity there is therefore no alternative to first calculating the elasticities of substitution from the cost function and then inverting the matrix to get the elasticities of complementarity.

\subsection{Elasticities of substitution}

The log cost function per unit of production in job type $c$ and per unit of consumption follows from substitution of the demand functions (4) and (6) for $f(s, c)$ and $y(c)$ in the production and utility functions (2) and (3):

$$
\left.p(c)=\frac{1}{1-\sigma} \ln \left[\int_{-\infty}^{\infty} \exp _{[} \hat{o} s c+(1-\hat{o}) w(s)\right] d s\right]
$$

aand:

${ }^{7}$ I assume constant returns to scale to be able to normalize the level of output to unity and to suppress it from the subsequent notation. 


$$
\left.p_{x}=\frac{1}{1-c ̧} \ln \left[\int_{0}^{\infty} \exp \operatorname{ls}_{[} h(c)+(1-c ̧) p(c)\right] d c\right]
$$

Substitution of equation (7) for $p(c)$ in (8) yields the log cost function per unit of consumption directly in terms of the wages per type of worker. The calculation of the economy-wide elasticities of substitution $c_{i j}$ between workers of type $s_{i}$ and $s_{j}$ is based on the second derivative of the log cost function: ${ }^{8}$

$$
c_{i j, i \neq j}=1+\frac{\mathrm{d}^{2} p_{x}}{\mathrm{~d} w\left(s_{i}\right) \mathrm{d} w\left(s_{j}\right)} /\left[\frac{\mathrm{d} p_{x}}{\mathrm{~d} w\left(s_{i}\right)} \frac{\mathrm{d} p_{x}}{\mathrm{~d} w\left(s_{j}\right)}\right]
$$

The equation for diagonal elements reads somewhat different, but is omitted for convenience.

As $w(s)$ is not a variable, but a function, the derivative $\mathrm{d} p_{x} / \mathrm{d} w(s)$ is not defined. My approach is to partition the domain of $s$ into a large but finite number of intervals. ${ }^{9}$ The intervals are numbered consecutively $i=1, I ; s_{i}$ denotes the boundary value between interval $i$ and interval $i+1$ and $w_{i}$ denotes the wage earned by workers whose $s$ falls within the $i$-th interval. The integral in (7) is replaced by the summation:

Ó$_{i=1}^{I}\left[s_{i}-s_{i-1}\right] \exp \left[\right.$ ós $\left.s_{i} c+(1-o ́) w_{i}\right]$.

Written in this way, the consumption price $p_{x}$ is a function of the log price $w_{i}$ of the inputs

${ }^{8}$ Let $\mathbf{H}$ be the matrix of elasticities of substitution ( $c_{i j}$ being its $\{i, j\}$-th element). The standard expression for $\mathbf{H}$ is:

$\mathbf{H}=C \mathbf{C}_{\mathrm{P}}^{-1} \mathbf{C}_{\mathrm{PP}} \mathbf{C}_{\mathrm{P}}^{-1}$,

where $\mathbf{C}_{P}$ is a diagonal matrix with: DIAG $\left[\mathbf{C}_{P}\right]=\underline{C}_{P}$ (other symbols have been defined in Section 4.1). The difference between this and equation (9) is that there the log of factor prices is the arguments of the log cost function.

${ }^{9}$ The subsequent results can also be derived by applying a variational argument, e.g. Chiang (1992), which is both easier and more standard mathematically. I nevertheless applied this 'discretization' approach since it allows the matrix inversion required for the calculation of the elasticities of complementarity. 
$i=1, I$. Standard methods for the calculation of elasticities of substitution and complementarity can be applied. For large values of $I$, the above summation can be approximated by the integral in (7) and $w(s)$ for $s_{i-1}<s<s_{i}$ converges to $w_{i}$.

For the sake of convenience, we switch back to the notation based on a continuous variation of $s$, keeping in mind the analogy with discrete variation. By this analogy, the elasticities of substitution $\mathrm{c}_{i j}$ can be calculated from equation (9) as:

$$
\mathrm{c}_{i j, i \neq j}=\mathrm{c}_{\mathcal{1}}+\left(\mathrm{o}^{-} \mathrm{c}\right) \frac{\int_{0}^{\infty} \exp x(c)+a\left(s_{i}, c\right)+a\left(s_{j}, c\right) \mathrm{d} c}{\int_{0}^{\infty} \exp x(c)+a\left(s_{i}, c\right) \mathrm{d} c \int_{0}^{\infty} \exp x(c)+a\left(s_{j} ;\right.}
$$

where:

$x(c) \equiv c ̧ h(c)+(1-c ̧)\left[p(c)-p_{x}\right]$

$a(s, c) \equiv \hat{o} s c+(\hat{o}-1) p(c)$.

By equation (6), $x(c)=y(c)+p(c)-x-p_{x}$. Hence, $x(c)$ can be interpreted as the log value share of product type $c$ in consumption. Equation (10) is a complicated expression. However, for ó tending to infinity, it can be simplified, as shown in Appendix 1. The basic idea is to use second order Taylor expansions for the log integrands, e.g. in equation (7):

ósc + (1-ó) $w(s)=$ ó $s_{0} c+(1-o ́) w\left(s_{0}\right)+(1-o ́) w^{\prime \prime}\left(s_{0}\right)\left(s-s_{0}\right)^{2}+$ higher order terms, where $s_{\mathrm{o}}$ is defined in such a way that the first derivative is equal to zero. Since the second derivative is negative, the contribution of higher order terms to the value of the integral can be ignored when ó tends to infinity. Hence, we can apply the formulas for the integration of the normal distribution. This procedure yields the following expression:

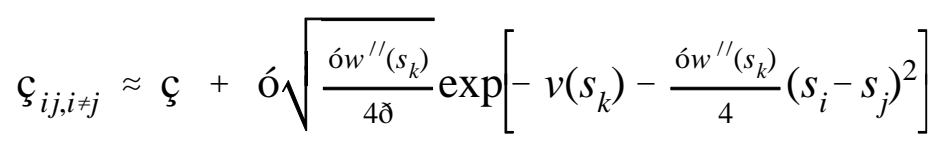

where: 
$s_{k} \equiv\left(s_{i}+s_{j}\right) / 2$

$v(s) \equiv e(s)+w(s)-x-p_{x}$.

$v(s)$ can be interpreted as the log value share of worker type $s$ in production.

Equation (11) yields three corollaries:

\section{Corollary 1:}

The elasticities exhibit the distance-dependent elasticity of substitution (DIDES) structure (Teulings 1992): the greater the gap between two types of workers measured in terms of $s$, the smaller is the elasticity of substitution.

\section{Corollary 2:}

The higher the value of $w^{\prime \prime}(s)$, the quicker the elasticity of substitution decreases with the skill gap between worker types.

\section{Corollary 3:}

$\lim _{\mathrm{o}_{-\infty}} \mathrm{c}_{i j}=\mathrm{c}_{3}, \forall i, j, i \neq j$.

The first two corollaries match the analysis in Section 2. A low-skilled worker is better substitute for a slightly better skilled worker than for a top specialist, which is in line with common sense observations. Increasing the wage for one skill type will induce substitution towards the skill types "at short distance". The higher the second derivative, the more kinked is the wage curve and the less likely it is that distant skill types will be affected by the wage increase, see Figure 1 . When $w^{\prime \prime}(s)=0$, all jobs are of equal complexity and hence the distance between skill types does not affect the elasticity of substitution, see Section 2.

Corollary 3 is probably more surprising. It states that almost everywhere the scope for substitution is equal to the between-job substitution ç. Within-job-between-skill type 
substitution is irrelevant. The analysis in Section 2 offers a clue, see Figure 1. Increasing $w(s)$ for small domain $\left(s^{-}, s^{+}\right)$will increase the demand for the neighboring skill types, $s^{-}$ and $s^{+}$, because these types are the new points of tangency to the productivity line with slope $c$, but not for skill types at greater distance. Elasticities of substitution are therefore a meaningless concept in this kind of world. We turn therefore to the calculation of their counterparts, the elasticities of complementarity.

\subsection{Elasticities of complementarity}

Due to Corollary 3, equation (11) cannot be applied for the calculation of elasticities of complementarity when ó $=\infty$. This is the reason why we have to consider a model with imperfect within-job substitution. First, the bordered Hessian matrix has to be inverted for $o<\infty$, and then we let ó go to infinity. The limiting matrix of elasticities of complementarity for ó tending to infinity will be shown to be well defined, independently of the precise value of $o$.

The analysis in Section 4.2 did not require a rule for the partioning of the domain of $s$ in intervals. However, the analysis in this section can be simplified by the choice of a convenient partitioning:

$s_{i}-s_{i-1}=\varnothing\left[I, w^{\prime \prime}\left(s_{i}\right)\right]^{-1}$,

where:

$\varnothing \equiv \int_{s-}^{s+} w^{\prime \prime}(s) \mathrm{d} s$

where $\left[s^{-}, s^{+}\right]$denotes the support of $s ;^{10} \varnothing$ is a weighted sum of $w^{\prime \prime}(s)$ and is therefore a measure of job heterogeneity. Were $\varnothing$ equal to zero, all jobs would be of the same complexity. Note that $\varnothing$ does not depend on either ó or $I$.

\footnotetext{
${ }^{10}$ So far, the support of $s$ was assumed to be unbounded. For the partioning used subsequently, a bounded support is required. We can expect that ignoring the extreme tails of the distribution of $s$ does not affect the results much. Define: $s_{0}=s^{-}$and: $\varnothing \equiv\left(s^{+}-s^{-}\right) /\left(\mathrm{O}_{i=1}^{I}\left[I \mathcal{w}^{\prime \prime}\left(s_{i}\right)\right]^{-1}\right)$. Then, the partioning in the text implies: $s_{I}=s^{+} . s_{i}-s_{i-1}$ can be written as: Äs/ ̈̈ $i$. For a large $I$, the trajectory of $s_{i}$ can be approximated by a continuous function with a well defined inverse. This first difference can then be interpreted as a derivative. Hence: ${ }^{\mathrm{d} i} /_{\mathrm{d} s}=\emptyset^{-1} I \mathcal{w}^{\prime \prime}(s)$. Its integral over the support of $s$ must be equal to $I$. This yields the expression for $\emptyset$ in the text.
} 
Substituting the expression for $s_{i}-s_{i-1}$ in equation (11) yields: ${ }^{11}$

$\mathrm{W}_{i j, i \neq j} \approx \mathrm{c}+\frac{\varnothing o ́}{v_{k} I} \sqrt{\frac{\sigma}{4 ð}} \exp \left[-\frac{o \phi^{2}}{4}\left(\frac{i-j}{I}{ }^{2}\right]\right.$

where:

$v_{i} \equiv \exp \left[v\left(s_{i}\right)\right]\left(s_{i}-s_{i-1}\right)$.

$v_{i}$ is the value share of the $i$-th skill type in production. Written in this way, the elasticities of substitution depend on two factors: i) a distance measure between two skill types based upon the curvature of the log wage function $w^{\prime \prime}(s)$, and: ii) the value share of each skill type. Note that the distance measure in i) is not defined independently of market equilibrium. Changing the distribution labor supply over $s$ or product demand over $c$ will affect $w(s)$ and hence $w^{\prime \prime}(s)$.

The approach which involves approximating the elasticities of complementarity for case of ó $=\infty$ and $I=\infty$ by the case where both parameters are set at some large but finite values makes sense only when the matrix of these elasticities converges to a limit. We have therefore to characterize the inverse of a matrix of an arbitrary large dimension. I do so for the special case of ç $=0$ and $v_{i}=I^{-1}$ (the latter value satisfies the constraint of the sum of the value shares being equal to unity) in Appendix 2. This characterization justifies the following conjecture:

\section{Conjecture:}

For large values of ó and $I$, for ç $=0$ and $v_{i}=I^{-1}$, the elasticities of complementarity $g_{i j}$ converge to:

${ }^{11}$ The effect of: $w^{\prime \prime}\left(s_{k}\right) \neq w^{\prime \prime}\left(s_{i}\right) \neq w^{\prime \prime}\left(s_{j}\right)$ is of higher order, compare similar arguments applied in Appendix 1. 


$$
g_{i j}=\frac{\phi^{2}}{2}\left[-\frac{i}{(I)}+2 \mathrm{IND}_{\mathrm{i}>\mathrm{j}\left(\frac{i-j}{I}\right)}+\frac{1}{3}-\left(1-\frac{j}{I}{ }^{2}\right]\right.
$$

where $I N D_{x}$ is an indicator function being equal to unity if $x$ is true and zero otherwise.

The index $i / I$ refers to the same skill type $s_{i}$, irrespective of the choice of $I$, see the definition of the partioning (mutatis mutandis the same for $j / I$ ). The elasticities of complementarity are therefore independent of both ó and $I$. The implications of this conjecture can be better understood from the following characteristics of the trajectory of $g_{i j}$ for a fixed $j$, see also Figure 2.

i) outside the main diagonal it is governed by a second order difference equation of the form: $\ddot{\mathrm{A}}^{2} g_{i j}=-\emptyset^{2} / I^{2}$, where $\ddot{\mathrm{A}}$ is the first difference operator;

ii) at the main diagonal it is discontinuous; the elasticities $g_{i j}$ are therefore points on two branches of the same parabola; at the main diagonal, both branches reach their minimum;

iii) at the boundaries of the matrix, for $i=1$ and $i=I$, the derivative of the parabola is zero; together, i) and iii) determine the slope of the trajectory of both branches of the parabola at the main diagonal;

iv) the sum of the elasticities $g_{i j}$ over $i$ equals zero; this determines the level of the trajectory.

The most remarkable feature of the trajectory is its discontinuity, causing the deep trough at main diagonal. The negative effect of an increase in the supply of a particular skill type on the wages of other skill types declines quickly with the skill distance. As discussed before, $\varnothing$ measures the dispersion of job complexity. The larger this parameter, the greater the effects of changes in supply and demand on relative wages. When all jobs are of equal complexity $(\varnothing=0)$, the wage of type $s$ is independent of supply and demand. The economic rationale is that, within this single job type, skill types are perfect substitutes (for: ó $=\infty$ ), differing only in their level of productivity.

The proofs in Appendix 2 reveal the second differential of the trajectory of $g_{i j}$ to be 
independent of ó even when ó is finite. ${ }^{12}$ In the more general case where the value shares $v_{i}$ are not evenly distributed across $i$, the second derivative is inversely related to $v_{i}{ }^{13}$ Figure 2 is helpful for understanding the importance of the aggregation bias in the estimation of elasticities of complementarity. These elasticities peak sharply at the main diagonal. When skill types are aggregated in a small number of broad categories, as is usually done for estimation, the elasticities at short skill distances will be greatly underestimated (in absolute value), because the trough in the elasticities is smoothed out.

This "smoothing out of the trough" has most impact when analyzing the effect of minimum wages, which explains the minimum wage paradox. An increase in the minimum wage is equivalent to a reduction in effective labor supply at the lowest skill level employed. The effect on wages should therefore be calculated from the elasticities of complementarity for the least skilled workers, for $i=1$ so to speak. This will necessarily be at the lower bound of a broad skill category, where the bias is at the maximum. The problem is aggravated by the fact that the diagonal elements reach a minimum for both extreme skill types, $i=1$ and $i=I$, as follows from the trajectory along the main diagonal:

$\emptyset^{2}\left[(i / I)-(i / I)^{2}-1 / 3\right]$.

The economic rationale for this conclusion is that the extreme types have suitable substitutes available only from one side, while for intermediate skill types both lower and higher skill types are good substitutes. Hence, the effect of aggregation will hurt most in the lowest and in the highest skill category.

${ }^{12}$ See in particular equation (20).

${ }^{13}$ See in particular characteristic ii) after Lemma 1 and how this would be changed by allowing: $v_{i} \neq I^{-1}$. 


\section{Estimation}

\subsection{Methodology}

In order to get an impression of the numerical implications of the previous analysis, estimates for the basic parameters of the model are required. Estimation refers to parameters of the labor market only, in effect equation (5). The between-job elasticity of substitution ç is not estimated. My approach is to make simulations for some values of ç, just to gain an impression of their impact on the results.

The estimation procedure is basically the same as in Teulings (1995a), with two improvements. I shall therefore discuss the main lines only in order to give the reader an idea. Likewise, I shall report only the main results. The reader interested in further details should consult Teulings (1995b). The idea is to estimate the model on data for individuals simultaneously for a number of economies, assuming the production technology within each job type to be the same across these economies. Where a number of papers suggest skill biased technological progress to be the main force driving the increase in the return to skill, this assumption seems inadequate. However, biased technological progress shifts the distribution of demand towards more complex jobs. With a proper definition of jobs, the within-job technology must remain the same. This idea is confirmed by the results of Juhn, Murphy, and Pierce (1993), who show that employment in occupation/industry cells employing highly skilled workers has increased relative to employment in cells with lowskilled workers. An occupation/industry cell can be interpreted as a job type. In fact, the same notion of a constant technology within jobs underlies the analysis of for example Katz and Murphy (1992) or Topel (1994), where the distribution of employment across industries is used to measure the shift in the skill composition of labor demand.

The estimation proceeds in two stages. In Stage 1, personal characteristics like years of education, experience, sex and race are viewed as components of the skill index. The relation between these characteristics and log wages is estimated for all economies simultaneously. Although the relation between skill index and wages varies between economies depending on the relative scarcity of skill, the contribution of each 
characteristic to the skill index is fixed across economies. This is the consequence of the single dimensionality assumption of skill types, see Section 2. In Stage 2, these estimates are applied to calculate the return to skill, $w_{t}^{\prime}(s)$ for each economy $t$. This measure of the return to skill is related to characteristics measuring job complexity, see equation (5). Both stages will be elaborated subsequently.

\section{Stage 1: personal characteristics and wages}

The analysis in Section 2 and 4 shows elasticities of substitution and complementarity to be determined mainly by the second derivative of the log wage function $w^{\prime \prime}(s)$. The problem in stage 1 is that we have no idea about the appropriate functional form of $w(s)$, except that $w^{\prime}(s), w^{\prime \prime}(s)>0$. Simply imposing a functional form that satisfies both constraints would imply that we fix the elasticities a priori instead of estimating them. The latent variable $q$ is therefore introduced; $s$ is defined by some increasing transformation of $q$ :

$s=S(q)$, $S^{\prime}()>0$.

which is constant across economies $t$. Hence:

$w=w_{t}[S(q)] \equiv W_{t}(q), \quad W_{t}^{\prime}()>0$.

where the subscript $t$ is introduced for both wage functions to stress the fact that wage functions differ between economies, contrary to $S($.$) . W_{t}($.$) is estimated in stage 1$, where a flexible functional form is applied. We shall be able to establish the shape of $S($.$) in$ stage 2 .

Suppose the relationship between the personal characteristics of worker $i$ in economy $t$ and this latent variable $q_{i t}$ to be:

$q_{i t}=x_{i t}^{\prime} \dot{a}+\underline{s}_{i t}$

where:

$x_{i t}: \quad$ a vector of characteristics of person $i$, excluding a constant;

á: a vector of parameters of corresponding dimension; 
$\underline{S}_{i t}: \quad$ a random variable, distributed as $\mathrm{N}\left(0, \underline{\hat{o}}^{2}\right)$, which is independent of $x_{i t}$.

á is assumed to be the same across economies. This is a parameterization of the single dimensionality assumption. We can normalize the value of ó to unity without loss of generality because a multiplicative transformation of $q_{i t}$ can always be offset by a compensating transformation in $W_{t}($.$) . In practice, we estimate not W_{t}($.$) , but its inverse.$ We use a polynomial in $w_{i t}$ as a flexible functional form. The estimation results refer to a fifth orde polynomial.

Minimum wages have had a considerable impact on the shape of wage distribution in the U.S. economy, in particular in 1979 (see for example the graphs in DiNardo, Fortin and Lemieux, 1996). Let $q_{t}^{*}$ be the value of $q_{i t}$ for which $W_{t}\left(q_{i t}\right)$ is equal to the minimum wage. $W_{t}($.$) and W_{t}^{\prime}($.$) are probably discontinuous at q_{t}{ }^{*}$. For $q_{i t}$ slightly below $q_{t}{ }^{*}, w_{i t}$ will either be zero (if the minimum wage legislation is fully enforced and no jobs are paid at below the minimum wage) or far below the minimum (partial enforcement, employers trading the risk of being penalized against a lower wage bill, see Chang and Ehrlich, 1985). Furthermore, Meyer and Wise (1983a,b) report a mass point (a spike) in the wage distribution at the minimum. Although the model can explain why the distribution creeps up against the minimum from the right, see Section 6, it cannot explain mass points. Probably, only a monopsony model can. I consider monopsony to be a second- order phenomenon relevant only for extremely low levels of the minimum, as in 1990. It will be ignored here. Meanwhile, the mass point must not interfere with the estimation of $W_{t}^{\prime}($.$) . For this reason, all observations below the minimum wage plus 1 \%$ are deleted. This selection does not endanger the validity of the estimation in Stage 2, since there $W_{t}^{\prime}($.$) is the exogenous variable. Following Meyer and Wise (1983a,b), a truncated model$ is fitted to the remaining data.

\section{Stage 2: job characteristics and the return to skill}

Stage 2 requires information on the complexity of the job held by each worker. Using equation (5) and the notation developed above, we have a relationship between job 
complexity and the return to the qualification $q_{i t}$ of the worker, all in economy $t$ :

$c_{t}\left[S\left(q_{i t}\right)\right]=w_{t}^{\prime}\left[S\left(q_{i t}\right)\right]=W_{t}^{\prime}\left(q_{i t}\right) / S^{\prime}\left(q_{i t}\right)$.

By taking logs, this equation can be written as:

$j_{i t}=\hat{\mathrm{a}}_{0}+\hat{\mathrm{a}}_{1} \ln W_{t}^{\prime}\left(q_{i t}\right)+B\left(q_{i t}\right)+\underline{u}$,

where $j_{i t}$ denotes the available information on job complexity (i.c. 30 dummies for occupations), where $\underline{u}$ measures unobserved job characteristics and where $B($.$) is a$ polynomial. ${ }^{14}$ In practice, a fourth order polynomial is applied. Then:

$\ln S^{\prime}\left(q_{i t}\right)=-B\left(q_{i t}\right) / \hat{\mathrm{a}}_{1}$.

Estimates for $W_{t}^{\prime}\left(q_{i t}\right)$ and $q_{i t}$ are available from Stage $1 .{ }^{15}$ Hence, estimation of $\hat{\mathrm{a}}_{0}, \hat{\mathrm{a}}_{1}$ and the parameters of $B($.$) is straightforward. Both the second and the third term on the right$ hand side are transformations of $q_{i t}$. Many commentators have therefore doubted whether the model is identified. However, the transformation $\ln W_{t}($.$) differs between economies$ (depending on the return to skill in each economy), while the transformation $B($.$) does$ not. If the allocation of workers with qualification $q_{i t}$ to jobs with index $j_{i t}$ was fixed across all economies $t$, the coefficient $\hat{\mathrm{a}}_{1}$ for the variation in the return to $q_{i t}$ would be estimated to be equal to zero. It is the variation in the relationship between $j_{i t}$ and $q_{i t}$ across economies that allows the identification of both terms. This is an analogon of the standard conclusion that supply or demand curves can only be identified when variation in market equilibria is available.

A test of the model is whether the second-order condition, $w_{t}^{\prime \prime}(s)>0$, is satisfied for all $t$ and all $s$. We have: $w_{t}^{\prime}(s)=W_{t}^{\prime}(q) / S^{\prime}(q)$. Hence:

$w_{t}^{\prime \prime}(s)=W_{t}^{\prime \prime}(q) / S^{\prime 2}(q)-W_{t}^{\prime}(q) S^{\prime \prime}(q) / S^{\prime 3}(q)>0$,

${ }^{14}$ This equation deviates from the one applied in Teulings (1995a) in that $j_{i t}$ instead of $\ln W_{t}^{\prime}\left(q_{i t}\right)$ is the endogenous variable. The present approach is an improvement, since it accounts for the selection bias due to the fact that we do not observe job opportunities which employers choose to leave open, see Teulings (1995b, Section 4.2). The equation that is actually estimated does not use $j_{i t}$, but a flexible transformation (i.c. a third order polynomial) of $j_{i t}$ as the endogenous variable, but this does not make much difference for the argument.

${ }^{15}$ As direct information on $q_{i t}$ is not available (only the observable characteristics), I use the estimation results for $W_{t}\left(q_{i t}\right)$ from Stage 1 to recover $q_{i t}$ from $w_{i t}$. 
or: $\mathrm{d} \ln W_{t}^{\prime}(q) / \mathrm{d} q>\mathrm{d} \ln S^{\prime}(q) / \mathrm{d} q$.

From the point of view of the substitutability of skill types, the crucial parameter is the dispersion of $c$ (see the discussion on the parameter $\varnothing$, in Section 4). The previous discussion gives the reader an insight in the information that allows the identification of this parameters. Inference is based on an inter-economy comparison of variation in the return to the skill index $W_{t}^{\prime}\left(q_{i t}\right)$ and variation in the allocation of workers (characterized by $q_{i t}$ ) to jobs (characterized by $j_{i t}$ ). The larger the variation in the return to the skill relative to that in the allocation of workers to jobs, the greater the dispersion of job complexity. When variation in the allocation yields no variation in the wage structure at all, all jobs are of equal complexity.

\section{$\underline{5.2 \text { Data and estimation results }}$}

The estimation results refer to the US economy, with the exception of Alaska and Hawaii. They are based upon CPS data for 1973, 1979, 1985 and 1990. All four years are close to or at the top of the cycle so as to eliminate cyclical fluctuations in relative wages. The four main regions are viewed as separate economies, so that the model is estimated for 16 economies (4 years $\mathrm{x} 4$ regions) simultaneously. Since we are interested in substitution between labor inputs of different skill types, a sample is required that is representative of the work force by hour. In order to get such a sample, a proportion of the part-timers are deleted. A full-timer is assumed to work 40 hours a week. A part-timer working 20 hours is deleted with probability a half; a part-timer working 10 hours is deleted with

probability $0.75 .^{16}$ Furthermore, all self-employed persons are deleted. Following this selection and after deleting all observations for which crucial information is missing, a sample of about 5,000 observations is drawn randomly for each of the 16 economies, yielding a dataset totalling about 80,000 observations. After deletion of observations for which the hourly wage rate is below the minimum wage plus $1 \%$, we are left with 74,453

${ }^{16} \mathrm{~A}$ more efficient alternative would be to impute weights in the likelihood function. However, due to the large number of observations available, I can afford some loss of information. The approach in the paper is more convenient. 
observations.

Table 1 reports the estimation results for Stage 1, the relation between worker characteristics and wages. Following the analysis of Murphy and Welch (1990), a thirdorder term for experience is included. For education, the variable "highest grade attained" and four dummy variables are included: high school completed, and 2, 4 and 6 years of college completed. Furthermore, there are dummies for marital status (single vs. married/divorced/widowed) for each sex and a dummy for black people. Tenure is not included in the analysis, because of the endogenous nature of this variable.

The values for á's are in accordance with the results from ordinary wage regressions. Their absolute value can be appreciated by noting that the standard deviation of the residuals is normalized to unity. As the root mean squared error is about 0.40 in an ordinary wage regression, á has to be multiplied by that number to make it comparable to the coefficients from these regressions.

The single dimensionality assumption that á's are equal across economies can be tested by estimating the model separately for (subsets of) the 16 economies in the analysis. If the single dimensionality assumption was correct, these separate models would not predict wages more accurately. This test is very strict: one can hardly expect that the assumption that á is equal across markets will hold exactly. ${ }^{17}$ Two statistics of this type are calculated, by running the model separately, firstly for each region, and secondly for each year. The sum of the log likelihoods for each region and for each year are reported in Table 1. Although the single dimensionality assumption is rejected, it performs fairly well. For example, allowing for non-linearity in $W_{t}($.$) is a more important contribution to the$ likelihood than allowing for differences in á between regions or years. Teulings (1995b) also reports log likelihoods for different orders of the polynomial for the inverse $W_{t}($. than the value of 5 that is applied here. A higher order for the polynomial improves the

\footnotetext{
${ }^{17}$ For example, consider the evidence of Katz and Murphy (1991) and Juhn, Murphy and Pierce (1993) on the differences in the timing of the rise in the return to education on the one hand and to experience on the other.
} 
$\log$ likelihood significantly.

Embedded in the single dimensionality restriction is the restriction that ó varies proportionally to coefficients for the other personal characteristics. This due to the fact that ó is normalized to unity for all markets, so that its ratio to the elements of á is the same across markets. Several researchers have reported a rise in the residual variance of wage equations over time. The constancy of $\underline{o}$ is justified if this rise is due, not to increased dispersion of unobserved characteristics, but to an increased pay-off for these characteristics. Juhn, Murphy and Pierce (1993) present evidence supporting this conclusion. The test statistics above suggest that the interpretation of an increased pay-off is easily squared with the data.

A convenient way to get a feel for the estimation results is a plot of the return to the skill index $q, W_{t}^{\prime}(q)$ for each economy $t$. In figure 3 , this return is plotted as function of the wage level $w$. The return is normalized by dividing by 0.4 (the standard deviation of the residuals in a standard earnings equation), so that the return will be about unity on average. Each region is presented in one panel. The four graphs in each panel refer to the years in the sample. For each $t$, wages are scaled relative to the median wage level for the sample used for estimation (hence excluding observation $\leq$ minimum wage). Hence, $w=$ 0 corresponds to the median. The vertical line represents the position of the minimum wage in each economy.

Figure 3 reveals a clear pattern. For each economy, the return to the skill index is inversely related to the level of the minimum, in particular in the bracket of the wage distribution just above the minimum. Hence, the return is low in 1979 and in the south region $^{18}$. Apparently, minimum wages cause wage differentials in the bracket just above the minimum to be compressed. As will be discussed in detail in Section 6, this outcome squares precisely with the predictions of the DIDES model, where increases in the minimum wage have substantial spill-over effects to wages just above the minimum. Note that this conclusion is not driven by the assumptions on absolute or comparative

\footnotetext{
${ }^{18}$ Minimum wages in the south are higher relative to the median because nominal wages are 5-10\% lower in the south than in the rest of the country.
} 
advantage. The only assumption required for the estimation results till sofar is the single index assumption for $q$. Teulings (1998) works out a formal method to use similar plots for the evaluation of the effect of minimum wages on the wage distribution. His conclusion, in line with the results of Lee (1998), is that the reduction in real minimum wages is the most important factor explaining the rise in wage dispersion in the eighties.

The index for job complexity, $j_{i t}$, is based on a classification of three-digit occupational codes into 30 groups. Details of this classification are discussed in Appendix $3 . j_{i t}$ follows from running the following regression:

$x_{i t}{ }^{\prime} a ́=o_{i t}{ }^{\prime} \ddot{a}+\underline{v}$,

where $o_{i t}$ is a vector of 30 dummies for each occupational group, $\ddot{a}$ is a vector of regression coefficients and $\underline{v}$ is an error term, and where the estimated values for $a$ are used to calculate $x_{i t}{ }^{\prime a ́}$. Then: $j_{i t} \equiv o_{i t}{ }^{\prime} \ddot{a}$. The coefficients $\ddot{a}$ (normalized on a $0-1$ scale) are reported in Table 2.

Like the single dimensionality assumption for $s$, the single dimensionality assumption for $c$ can be tested by running separate regressions for each region and for each year. If the single dimensionality assumption was a perfect description of reality, the variations in the return to skill would explain all the variation in the allocation of skill to job types across economies. Take the case where we do not allow for any variation in the allocation as a benchmark. The return to skill explains $15 \%$ of the difference between the log likelihood of this benchmark case and the case where we estimate the model for each year separately. The second-order condition $w^{\prime \prime}(s)>0$ is satisfied for all $t$ and all $s$. 
$\underline{6 \text { Some simulations }}$

\subsection{Elasticities of complementarity}

Elasticities of complementarity can be calculated by applying the Conjecture of Section 4 and the estimation results in Section $5 .{ }^{19}$ The estimation results provide three ingredients for our exercise: i) the wage function $W_{t}(q)$, ii) the transformation of $q$ into $s, S(q)$, and iii) the density function of wages, $d_{t}(w) .{ }^{20}$ The latter is required to calculate the value share $v_{i}$ of each skill type. All other variables in the model can be derived by applying a number of simple identities discussed throughout Section 3, 4, and 5. The only relevant parameter for which no estimate is available is the between-job elasticity of substitution, ç. I shall present calculations for both $\mathrm{c}=0$ and $\mathrm{c}=1$.

The elasticities of complementarity can be presented in various ways. One possibility is to look at the effect on the wage of type $i$ in $\%$ of an increase in the supply of type $j$ by $1 \%$, which is equal to $g_{i j} v_{j}$. The value share $v_{j}$ in each category is inversely related to the number of categories $I$. In order to eliminate this dependence on $I, g_{i j} v_{j}$ should be scaled by the share of labor supply of skill type $j$, denoted $d_{j} ; g_{i j} v_{j} / d_{j}$ measures the effect on the wage of type $i$ in $\%$ of an increase in the supply of type $j$ by $1 \%$ of the total labor force. Table 3 reports the elasticities $g_{i j} v_{j} / d_{j}$ for the south in 1979 and 1990. The results are in line with the theoretical analysis in Section 4. The wage effects of an increase in the supply for a particular type peak sharply at the own type, the more so for the highest and the lowest type, where substitutes are available only from one side, while intermediate types can be substituted for both slightly more and slightly less skilled worker types.

${ }^{19}$ In fact, equation (12) instead of the Conjecture is used. The assumptions $v_{i}=I^{-1}$ and $c ̧=0$ for which the Conjecture applies will not hold in the real world. Hence, matrix inversion is done numerically, with $I$ set to 400 and ó to 1600 . Some experimentation showed that variation in these parameters had little impact on the results.

${ }^{20}$ The estimation procedure for the density function is not discussed in Section 4. A flexible functional form is applied, comparable to the polynomial fitted to $W_{t}(q)$ (see Teulings (1995b) for details). 
Contrary to our present understanding (see Hamermesh, 1993, pp. 113-127), the elasticities are greater (in absolute value) for low-skilled than for highly skilled workers. The between-job elasticity of substitution, ç, turns out to be of limited importance for the values of elasticities of complementarity. Within-job-between-skill substitution is a more important force than between-job substitution. One should therefore be careful when basing inferences about the distributional effect of shifts in labor supply on between-job elasticities of substitution.

For low-skilled workers, the trough at the main diagonal is far more pronounced for 1990 than for 1979. The plots in Figure 3 are useful for getting an intuition for this result. The return to the skill index $q$ in the lower tier of the market is lower in 1979 than 1990: the high minimum wage has stongly compressed wage differentials for low-skilled workers in 1979. By the assumption of absolute advantage, the return to the skill index must be positive. Hence, there is less scope for further compression of wage differentials in the lower tier of the market in 1979 than in 1990. In 1979, any wage increase for the first percentile will therefore necessarily apply almost alike for all other workers in the lower quintile.

The results in table 3 can be directly compared to estimates of similar elasticities by Altonji and Card (1991). In their most preferred estimate, an inflow of migrants of $1 \%$ point of the labor force reduces the wages of the groups competing most directly with the entrants (in particular, low-skilled black women) by $1.6 \%$. This number is smaller (in absolute value) than the effects for the lower tier of the labor market reported in Table 3, but this might be explained by the broad skill categories applied by Altonji and Card. ${ }^{21}$ A comparison with the results of Topel (1994, Table 3) yields further insights into the impact of aggregation bias. Topel categorizes labor supply by level of education and sex into 5 classes, 3 for males and 2 for females. For comparison, labor supply in this study is divided into five quintiles. The low-skilled men in Topel's study are comparable

\footnotetext{
${ }^{21}$ When Altonji and Card account for differences in the level of schooling of immigrants the estimated effect rises from $1.6 \%$ to $12 \%$, but also becomes very imprecise.
} 
approximately to the second skill group in this study. Table 4 summarizes the effect of a $1 \%$ increase in labor supply on the median wage for all quintiles (the sum of $g_{i j} v_{j}$ for all $j$ in a quintile, where $i$ is the median of the quintile of which the wage is analyzed) for 1979 and 1990. For comparison with table 3, these numbers should be divided by the employment share in the quintile, which is 0.20 by definition.

Compared to the own elasticities of complementarity reported by Topel (about -0.60 ), the diagonal elements in Table 4 are slightly lower, in particular for ç $=1{ }^{22}$ However, the results in Table 4 are roughly consistent with Topel's findings. However, Table 3 reveals the divergence in elasticities of complementarity within broad skill categories hidden in Table 4. For 1990, aggregation reduces the own wage elasticity for the lowest percentile by a factor 2.5 ! For 1979, the consequences of aggregation are less severe. The reason for this difference is again the compression of wage differentials in 1979 due to the high minimum wage. There are almost no opportunities left for further relative wage changes within the lower quintile. Hence, aggregation is less harmful.

\subsection{The effect of minimum wages on employment and wage distribution}

The results in Table 3 and 4 clarify the minimum wage paradox. Like Topel (1994), most studies use rather broad skill categories for estimating elasticities of complementarity. This approach underestimates (in absolute value) the value of these elasticities at short skill distances. However, these are the relevant parameters for the analysis of the effects of minimum wages because a change in the minimum wage changes the effective supply of the lowest skill type. Furthermore, the own-elasticities of complementarity are larger for the extreme than for intermediate skill types, see Figure 2 in Section 4.

The effects of an increase in the minimum wage are shown in Figure 4. An increase in the

\footnotetext{
${ }^{22}$ The procedure for comparison can be expected to yield a somewhat lower estimate (in absolute value) than that found by Topel (1994) due to the assumption that the increase in supply is divided proportionally over all skill categories in a quintile, while in reality the increase will be concentrated around the median. This concentration yields a higher effect on the median wage in Topel's procedure, compare Figure 1.
} 
minimum is equivalent to the elimination of the least skilled worker types from labor supply. Due to the distance dependence of the elasticities of substitution (DIDES) structure, the wages of slightly better skilled workers will rise, while the wages for the best skilled workers will fall. The wage function is therefore twisted towards a lower return to skill along the whole schedule. The elasticities of complementarity reported in Table 3 suggest the break-even point to be between the 40th and 50th percentile of the distribution of labor supply. The wage distribution creeps therefore up towards the minimum.

The increase in the minimum from wmin $_{1}$ to wmin $_{2}$ an be broken down into two components, see Figure 4. The first component is the wage differential between the least skilled worker employed before and the least skilled workers employed after the minimum wage increase, measured on the wage schedule applying before the increase, $w_{m i n}{ }^{*}$ $w_{m i n}$ in Figure 4. This is the well-known metaphor that raising the minimum wage cuts off the lower part of the productivity distribution, see for example Meyer and Wise (1983a,b). I shall refer to it as the truncation component of the minimum wage increase. The second component is the wage increase for the least skilled worker employed due to the elimination of less skilled workers from supply. This component is measured by the difference between both wage schedules, $w \min _{2}-w m i{ }^{*}$ in Figure $4 .{ }^{23}$ I shall refer to it as the compression component, since it compresses skill differentials.

The distribution of the labor supply is assumed to be fixed. The higher wages for the worker types just above the least skilled type still employed are therefore assumed not to attract additional labor supply. Allowing for a supply effect would reduce the compression component in the minimum wage increase, since the lower effective supply of the least skilled types would be partly offset by an increase in the supply of slightly

\footnotetext{
${ }^{23}$ Meyer and Wise (1983a,b) implicitly assume relative wages to be fixed by imposing perfect substitution between worker types. They attribute therefore the whole increase to the first component. This yields an overestimation of the disemployment effect because there are fewer workers with a skill level just below the minimum than is expected when taking relative wage as being invariant to changes in the minimum. This overestimation is partly compensated for by the way the spike at the minimum is treated.
} 
better skilled types.

The calculation proceeds in reverse order. We start from the loss of employment by setting supply in the least skilled categories at zero. The supply in these categories measures the disemployment effect. Next, the required increase in the minimum can be calculated as the sum of both components discussed previously. For example, assume that supply in the lowest five skill categories $(j=1,5)$ is set at zero. The employment loss is equal to: $\mathrm{O}_{j=1}^{5} d_{j}$. The magnitude of the productivity cut-off component is $w_{6}-w_{1}$, that of the complementarity component is equal to: $\mathrm{O}_{j=1}^{5} g_{5 j} v_{j} \cdot{ }^{24}$ Since the results for ç $=0$ are the closest to Topel's estimates (1994), ç is set at zero for the calculations at hand.

This framework is applied to simulate the effects of an increase in the minimum wage starting from the wage distributions in the south for 1979, 1985, and 1990, see Table 5. The minimum wage is most binding in this region since average wages are 5-10\% lower there than in the rest of the country. For each year, the effects on employment are listed for an increase in the minimum of $5 \%, 10 \%$, and $20 \%$. Furthermore, the breakdown of the increase in the truncation and the compression component is presented.

For each year, employment effects increase linearly with the magnitude of the minimum wage increase. However, across years, there are substantial differences, the employment effects being smaller in 1990 than in 1979. This is due both to the truncation and the compression effect, as can be seen from the ratio of both components to the employment effect. For the truncation effect, the mechanism is obvious. The further left in the lower tail of the wage distribution, the smaller will be the density. The effect on employment of an increase in the truncation threshold will therefore be smaller when starting from a low value of the minimum wage.

For the compression effect, the discussion on the results in Table 3 provides a clue. In 1979, when the wage structure in the lowest quintile is strongly compressed, there is little scope for further compression. Hence, the compression effect of an increase in the minimum is much smaller. The ratio of the compression effect to the employment loss for

\footnotetext{
${ }^{24} \mathrm{~A}$ similar calculation for $i>5$ yields the effect of the minimum wage increase on the wages for higher skill types.
} 
1979 and 1990 corresponds roughly to the elasticities of complementarity for the second percentile listed in Table 3 , as is to be expected. ${ }^{25}$

The differences in the calculated employment loss for equal increases in the minimum for 1979 versus 1990 suggest that the linearity of the effects within a year in Table 5 should be dealt with cautiously. The employment effects of a $20 \%$ increase in the minimum in 1990 can probably be estimated more accurately by first using the results for 1990 to calculate the employment loss of the first $10 \%$ increase (bringing the minimum wage close to its 1985 level) and nextly using the results for 1985 for the next $10 \%$ increase. This procedure yields a higher estimate for the employment loss than directly applying the numbers for 1990. The reason for this phenomenon is that after having increased the minimum wage by $10 \%$, the employment loss of further increases is larger than given in Table 5 because the elasticities of complementarity are reduced, see Table 3 . Hence, the truncation component accounts for a larger share in the minimum wage increase.

The importance of the compression effect is strong evidence against the Meyer and Wise (1983a,b) model on the employment effect of minimum wages. They assume the wage distribution above the minimum to remain unaffected by changes in the minimum. This assumption is clearly rejected by the results presented in this paper.

A $10 \%$ minimum wage increase yields an employment loss of $0.8 \%$ in 1990, suggesting an overall elasticity of employment with respect to an increase of the minimum wage of 0.13. For 1979, this elasticity is higher. Even the number for 1990 is still substantially higher than the elasticities mentioned in Brown, Gilroy and Kohen (1982), who report elasticities of the employment for youngsters in the range of $0.10-0.30$. Since youngsters are only small proportion of total employment, the elasticity with respect to total employment is an order of magnitude lower. ${ }^{26}$ However, the DIDES model goes a long

\footnotetext{
${ }^{25}$ The employment loss for the lowest skill category $j=1$ is equal to $d_{1}$. The compression effect is $g_{11} v_{1}$. Hence, the ratio is $g_{11} v_{1} / d_{1}$, which is listed in Table 3 .

${ }^{26}$ Clearly, a Walrasian model like the one in this paper is incapable of generating the positive employment effects of higher minimum wages reported by Card and Krueger (1994). I tend to interpret these positive effects as second-order phenomena becoming relevant only for very low values of the minimum wage (as in 1990).
} 
way towards offering an explanation for the minimum wage paradox.

The framework can also be applied to evaluate the employment effect of $28 \%$ reduction of the real minimum wage between 1979 and 1990. Figure 5 shows the actual distributions of log wages $w$ (in the south-west quadrant) and the skill index $q$ (in the north-east quadrant). ${ }^{27}$ Wages are in 1979 dollars. The distribution of the skill index has a much fatter left tail in 1979, which is probably due to the large cohort size of youngsters in that year, who show up at lower end of the skill distribution due to their lack of experience. The lower (vertical) thresholds for the skill distributions in both years are the skill levels which earn exactly the minimum wage for that year. Less skilled workers are not employed. As was to be expected, the lower threshold is higher in 1979 than in 1990: the high minimum wage in 1979 discards least skilled workers from employment. These thresholds correspond to those (horizontal) for the wage distributions, which are equal to minimum wage for each year. The wage distribution for 1979 has a concentration of probability mass just above the minimum, while the distribution for 1990 is nicely bell shaped. The relation between wages and the skill index, $W_{t}(q)$ is depicted in south-east quadrant. As is discussed in relation to Figure 3, the derivative $W_{t}^{\prime}(q)$ is low in the wage bracket just above the minimum, the more so the higher is the minimum wage. In Figure 5 , this phenomenon translates into a flatter trajectory for $W_{t}(q)$ in the lower part of the skill distribution in 1979 than in 1990.

The dotted lines are the counterfactuals for 1990 using the minimum wage for 1979. The skill distribution is kept constant at its 1990 level (apart from the truncation of the left tail due to increase in the minimum wage), so that there is no counterfactual. By construction, the horizontal threshold (i.c. the minimum wage) for this counterfactual coincides with the threshold for 1979. However, the equality of the vertical threshold (i.c. the lowest skill

${ }^{27}$ The density of $q$ is equal to: $d_{t}(w) \mathrm{d} w / \mathrm{d} q=d_{t}(w) W_{t}^{\prime}(q)$. I present the distribution of $q$ instead of $s$ because it is easier to interpret as $q$ is close to the standard human capital specification in a Mincerian earnings equation. The index $q$ has been multiplied by a factor 0.4 , to make its unit of measurement comparable to that of $w$, see the discussion on Figure 3. 
type employed) is pure coincidence. The dotted lines in the south-east and the south-west quadrants represent the wage function and the wage distribution respectively. The counterfactual wage function for 1990 turns out to be almost identical to the wage function for 1979. According to DIDES model, the compression effect of raising the minimum wage from its 1990 to its 1979 level would therefore undo most of the rise in wage dispersion during the eighties, in particular in the left tail of the wage distribution. This result squares nicely with the conclusions of Lee (1998) and Teulings (1998), who both asses the effect of minimum wages on the wage distribution directly, by using the minimum wage as an explanatory variable for wage distribution and return on human capital. In the present study, the results on minimum wages presented in Figure 5 can in no way be an artefact of the estimation procedure. The estimates of the elasticity structure are based on inter-economy covariation of the return to the skill index and the allocation of worker types to job types, not on variations in the minimum wage. That the model nevertheless produces sensible results on the effects of minimum wages adds to its credibility.

\section{Conclusions}

My analysis has revealed a large aggregation bias in most estimates of elasticities of complementarity. The effect of increasing the supply of a particular, narrowly defined worker type on its own wage is up to a factor 2.5 larger than emerges from the standard estimation results. This aggregation bias offers at least a partial resolution of what I call the minimum wage paradox. Both the employment effects of minimum wages and the elasticities of complementarity are estimated to be small. However, apart from monopsony, the only explanation for the limited employment effects of minimum wages is that most of an increase in the minimum is swamped by an increase in the wages for the least skilled workers. However, such a wage increase requires the elasticities of 
complementarity to be large. ${ }^{28}$

My analysis is based on a simple and transparent economic principle, going back to the days of Ricardo: comparative advantage. The analysis deals with the consequences of this principle for the structure of substitution in an economy. The key result is the Distance Dependent Elasticity of Substitution (DIDES) characteristic: skill types are more easily substitutable the shorter the distance between the types in terms of the skill level. This characteristic squares well with the reader's a priori intuition. Two further analytical results are probably more surprising. First, elasticities of substitution are zero (or more precisely: equal to the between-job elasticity of substitution) for almost all pairs of skill types. The intuition is that under comparative advantage the neighboring skill types are an almost perfect substitute, rendering substitution to other skill types at greater distance meaningless. Or, using the DIDES metaphor, elasticities of substitution are so extremely dependent on the skill distance that they converge to zero even at a short distance. The second result refers to elasticities of complementarity. Consider a row of the matrix of these elasticities. This row can be represented as a function. It has a minimum at the diagonal element: increasing supply of a particular type has the biggest effect on the own wages. However, the surprising feature is that it is non-differentiable at diagonal. This yields a deep trough in its trajectory, see Figure 2 in Section 4. It is this trough, which is smoothed out by aggregation in broad skill classes, that is responsible for the large aggregation bias.

A look at simple pictures of wage distributions, such as provided by DiNardo, Fortin, and Lemieux (1996), offers convincing evidence for the relevance of the comparative advantage/DIDES model. These reveal a strong tendency for the wage distribution to creep up against the minimum wage when the minimum is increased. Although this feature is probably not a great surprise to the reader, the DIDES model offers the formal underpinning that has not till now been available. For example, most of the literature in

\footnotetext{
${ }^{28}$ In some sense, this paper is a late echo of Rosen's (1974: 51) suggestion of applying hedonic models to evaluate the impact of minimum quality standards on the economy. This suggestion has turned out to be fruitful.
} 
this field applied a CES technology. This assumption on technology will never yield the type of shifts in the wage distribution due to changes in the minimum wage that are observed empirically and produced naturally by a DIDES model.

One might argue that my approach suffers the disadvantage of being heavily parameterized. However, the four main assumptions laid out in Section 2 are far less restrictive than the arbitrary assumptions required for a CES model. ${ }^{29}$ To name a few: i) a classification of individuals within broad skill groups, ii) perfect within-skill-group substitution, iii) equal between-group elasticities of substitution. Obviously, one can eliminate assumption iii) by applying some of Diewert's translog or generalized Leontieff specifications. Assumptions i) and ii) will remain indispensable. Given the evidence on the importance of aggregation bias, this is an important drawback to this type of approach. Bearing in mind the above evidence on the magnitude of the aggregation bias, avoiding aggregation altogether by distinguishing an infinite number of skill types is a fruitful avenue to travel. The methods laid out in this paper can likewise be applied to other markets where different quality types are close substitutes, like the housing market. In comparison with the black box representation of the substitution process in CES functions, the principle of comparative advantage is intuitively appealing. In the comparative advantage model, the economy is explicitly modelled as an infinite number of interrelated labor markets for each skill type. This feature highlights the fluidity of the substitution process, where an increase in supply or demand in one market has spill-over effects on all other markets, the more so the shorter the skill distance. Further work will reveal some cook book recipes for applying these models, so that their complexity will no longer be an obstacle. Obviously, the model can be improved, for example by allowing different degrees of substitutability between labor and capital for each skill type. These are merely amendments to the main philosophy.

The practical implications of the analysis are huge. For example, on the positive side, the

\footnotetext{
${ }^{29}$ Interestingly, most of the supply and demand shifters used by authors applying the CES framework (Bound and Johnson 1992; Katz and Murphy 1992; Juhn, Murphy and Pierce 1993) implicitly require the combination of absolute and comparative advantage applied in the present paper.
} 
influx of low-skilled immigrants into the United States may have had a larger impact on wage distribution than suggested by previous research. Or on the normative side, increasing wage dispersion probably becomes a less attractive strategy for combating lowskilled unemployment in Europe. The alternative of trying to affect the distribution of labor supply by extended education might be more feasible. 
Literature

Altonji, J. and D. Card (1991), "The effects of immigration on the labor market outcomes of less skilled natives", in: J. Abowd and R. Freeman, Immigration, trade, and the labor market, Chicago University Press, Chicago.

Amemiya, T. (1985), "Advanced econometrics", Basil Blackwell.

Bound, J. and G. Johnson (1992), "Changes in the structure of wages in the 1980s. An Evaluation of Alternative Explanations", in: American Economic Review, pp. 371392.

Brown, C., C. Gilroy and A. Kohen (1982), "The effect of the minimum wage on employment and unemployment", in: Journal of Economic Literature, pp. 487-528.

Bureau of the Census (1989), The relations between the 1970 and 1980 industry and occupation classification systems, Technical Paper no. 59, US Government Printing Office, Washington D.C.

Card, D. and A. Krueger (1994), Minimum wages and employment: A case study of the fast-food industry in New Jersey and Pennsylvania, The American Economic Review, pp. 772-793.

Card, D. and A. Krueger (1995), Myth and measurement, The new economics of the minimum wage, Princeton University Press.

Card, D. and T. Lemieux (1996), Wage dispersion, returns to skill, and black-white wage differentials, in: Journal of Econometrics, pp. 319-361. 
Chang, Y and I. Ehrlich (1985), "On the economics of compliance with the minimum wage law", in: Journal of Political Economy, pp. 84-91.

Chiang, A.C. (1993), "Elements of dynamic optimization", McGraw Hill, New York.

DiNardo, J., N.M. Fortin and T. Lemieux (1996), "Labor market institutions and the distribution of wages, 1973-1992", in: Econometrica (forthcoming).

Hamermesh, D.S. (1986), "The demand for labor in the long run", in O. Ashenfelter and R. Layard (eds) Handbook of Labor Economics, North Holland.

Hamermesh, D.S. (1993), "Labor Demand", Princeton University Press.

Juhn, C., K.M. Murphy, and B. Pierce (1993), "Wage inequality and the rise in the returns to skill", in: Journal of Political Economy, pp. 410-442.

Katz, L.F. and K. Murphy (1992), "Changes in relative wages, 1963-1987: supply and demand factors", in : Quarterly Journal of Economics, pp. 35-78.

Lee, D.S. (1998), Wage Inequality in the U.S. during the 1980s: Rising Dispersion or Falling Minimum Wage?, International paper, Princeton University.

MacDonald, G.M. (1982), "Information in production", in: Econometrica, pp. 11431162.

Meyer, R.H. and D.A. Wise (1983a), "Discontinuous distributions and missing persons: the minimum wage and unemployed youth", in: Econometrica, vol. 51, no. 6, pp. 1677-1698. 
Meyer, R.H. and D.A. Wise (1983b), "The effects of the minimum wage on the employment and earnings of youth", in: Journal of Labor Economics, vol. 1, no. 1, pp. 66-100.

Murphy, K.M. and F. Welch (1990), "Empirical Age-Earning Profiles", in: Journal of Labor Economics, pp. 202-229.

Pettengill, J.S. (1984), "Minimum wage laws with a continuum of worker qualities", internal paper, Virginia Polytechnic Institute and State University Blacksburg.

Rosen, S. (1974), "Hedonic prices and implicit markets: product differentiation in pure competition", in: Journal of Political Economy, pp. 34-55.

Sattinger, M. (1975), "Comparative advantage and the distribution of earnings and abilities", in: Econometrica, pp. 455-468.

Sattinger, M. (1993), "Assignment models of the distribution of earnings", in: Journal of Economic Literature, pp. 831-880.

Teulings, C.N. (1992), "The effect of minimum wages on wage distribution and employment using non-discrete-factor production functions", Research Memorandum 9214, Department of Economics, University of Amsterdam.

Teulings, C.N. (1995a), "The wage distribution in a model of the assignment of skills to jobs", in: Journal of Political Economy, pp. 280-315.

Teulings, C.N. (1995b), "A generalized assignment model of workers to jobs for the

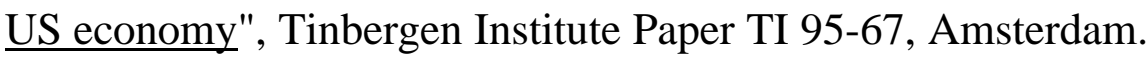


Teulings, C.N. (1998), "The contribution of minimum wages to increasing wage inequality", Internal paper, University of Amsterdam.

Topel, R.H. (1994), "Regional labor markets and the determinants of wage inequality", in: American Economic Review, pp. 17-22. 
Appendix 1 Derivation of approximation for the elasticities of substitution

Suppose the values of $w(),. e(),. x($.$) , and ç to be fixed and consider what happens when$ ó tends to infinity. For a fixed value of $c$, the following Taylor expansion for the intergrand in equation (7) in Section 3 applies:

ó $s_{0}(c) c-\left(\right.$ ó-1) $w\left[s_{0}(c)\right]-1 / 2(o ́-1) w^{\prime \prime}\left[s_{0}(c)\right]\left[s-s_{0}(c)\right]^{2}+\left(\right.$ ó-1) $\mathrm{O}\left[\left(s-s_{0}(c)\right)^{3}\right]=$ ó $s_{0}(c) c-(o ́-1) w\left[s_{0}(c)\right]-1 / 2 v^{2}+\mathrm{O}\left[o^{-1 / 2}\right] \mathrm{O}\left[v^{3}\right]$.

where $\mathrm{O}[$.$] is the standard order function { }^{30}$ and where $v$ is defined as:

$\left[(o ́-1) w^{\prime \prime}\left[s_{0}(c)\right]\right]^{1 / 2}\left[s-s_{0}(c)\right]$,

and where $s_{0}($.$) is implicitly defined by: (ó-1) w^{\prime}\left[s_{0}(c)\right] \equiv$ ó $c$.

By this definition, the first derivative of the integrand of (7) is zero for $s=s_{0}(c)$. Hence, the first-order effect drops out of the Taylor expansion above. Integrating out $v$ by applying the formula for the normal distribution, $p(c)$ can be written as: ${ }^{31}$

$\mathrm{D}$

$$
\begin{aligned}
p(c) & =-\frac{\sigma}{\sigma-1} s_{0}(c) c+w\left[s_{0}(c)\right]-\frac{1}{\sigma-1} \ln \left[\frac{1}{\sqrt{(\sigma-1) w^{\prime \prime}\left[s_{0}(c)\right]}} \int_{0}^{\infty} \exp _{-}-v\right. \\
& =-s_{0}(c) c+w\left[s_{0}(c)\right]+\frac{\ln (\sigma-1)}{2\left(\sigma^{-}-1\right)}+\mathrm{O}\left[\mathrm{o}^{-1}\right]
\end{aligned}
$$

ifferentiating equation (14) with respect to $c$ twice and applying the definition of $s_{0}($. yields:

$p^{\prime}(c)=-s_{0}(c)+\mathrm{O}\left[o^{-1}\right]$

$p^{\prime \prime}(c)=-s_{0}{ }^{\prime}(c)+\mathrm{O}\left[o^{-1}\right]=-1 / w^{\prime \prime}\left[s_{0}(c)\right]+\mathrm{O}\left[o^{-1}\right]<0$.

The latter equality follows from differentiating the definition of $s_{0}(c)$.

${ }^{30} f(x)=\mathrm{O}[x]$ means that $\exists B$ such that $\lim _{x \rightarrow 0}{ }^{*} f(x) / x^{*}<B$.

${ }^{31}$ The integral converges because $w^{\prime \prime}(s)>0$ for all $s$, see Section 2. Similar conditions will be available for all subsequent integrals that are handled in a similar way. 
Similarly, for a fixed $s$, a Taylor expansion for the function $x(c)+a(s, c)$ can be applied: $x\left[c_{0}(s)\right]+a\left[s, c_{0}(s)\right]-1 / 2 v^{2}+\mathrm{O}\left[\hat{o}^{-1 / 2}\right] \mathrm{O}\left[v^{3}\right]$.

where $v$ is defined as $\_$o $\left.\left[p^{\prime \prime}\left[c_{0}(s)\right]+\mathrm{O}^{-1} \hat{o}^{-1}\right]\right]^{1 / 2}\left[c-c_{0}(s)\right]$ and where $c_{0}(s)$ is implicitly defined by: $x^{\prime}\left[c_{0}(s)\right]+(o ́-1) p^{\prime}\left[c_{0}(s)\right] \equiv-o ́ s$.

It follows from this definition and the relation for $p^{\prime}(c)$ derived previously that: $p^{\prime}\left[c_{0}(s)\right]$ $=-s+\mathrm{O}\left[\hat{o}^{-1}\right]=-s_{0}\left[c_{0}(s)\right]+\mathrm{O}\left[\hat{o}^{-1}\right]$.

Hence, when ó tends to infinity, $s_{0}($.$) converges to the inverse function of c_{0}($.$) . Hence:$ $p^{\prime \prime}\left[c_{0}(s)\right]=-1 / w^{\prime \prime}(s)+\mathrm{O}\left[\hat{o}^{-1}\right]$.

Integrating out $v$ by applying the formula for the normal distribution and applying the last equality, the integrals in the denominator of equation (10) in Section 3 can be approximated by: ${ }^{32}$

$$
\ln \left[\int_{0}^{\infty} \exp [x(c)+a(s, c)] d c\right]=x\left[c_{0}(s)\right]+a\left[s, c_{0}(s)\right]+\frac{1}{2} \ln \left[\frac{2 \delta w^{\prime \prime}(s)}{\sigma}\right]
$$

Define: $q \equiv 1 / 2(u+r)$.

For the approximation of the numerator of (10), consider the function $x\left[c_{0}(q)\right]+a\left[u, c_{0}(q)\right]$ $+a\left[r, c_{0}(q)\right]$. By the definition of $q$, it is equal to $x\left[c_{0}(q)\right]+2 a\left[q, c_{0}(q)\right]$. By the definition of $c_{0}(q)$, the partial derivative of the latter function with respect to $c_{0}(q)$ is: $-x^{\prime}\left[c_{0}(q)\right]$, and the second derivative is: - ó $\left[2 / w^{\prime \prime}(q)+\mathrm{O}\left[o^{-1}\right]\right]$. Using a similar approximation for the integral in the numerator as is applied for the integrals in the denominator yields $:^{33}$

${ }^{32}$ Provided that $c_{0}(s)>{ }_{v}\left(w^{\prime \prime}(s) / 0\right)$, with $k$ is, for example, 4 . In that case, the truncation of the integral at the lower bound does not matter greatly because Ö(-4) is small, Ö(.) being the standard normal distribution function. Note that this difference converges to zero when: ó $\rightarrow \infty$.

${ }^{33}$ The expression $x\left[c_{0}(q)\right]+2 a\left[q, c_{0}(q)\right]$ is not the maximum of the integrand over $c$, as its derivative for $c=c_{0}(q)$ is equal to $x^{\prime}[c]$. Hence, the first order term does not drop out. However, the deviation of the maximum is of order $\mathrm{O}\left[\mathrm{o}^{-1}\right]$ as the second derivative is of order O[ó]. Hence, this deviation is covered by the approximation term in (16). 


$$
\ln \left[\int_{0}^{\infty} \exp [x(c)+a(u, c)+a(r, c)] d c\right]=x\left[c_{0}(q)\right]+2 a\left[q, c_{0}(q)\right]+\frac{1}{2}
$$

By the definition of $c_{0}(q)$, the following Taylor expansion applies:

$$
\begin{aligned}
x\left[c_{0}(u)\right]+a\left[u, c_{0}(u)\right]+ & \frac{1}{2} \ln \left(\frac{2 \delta w^{\prime \prime}(u)}{\sigma}\right)=x\left[c_{0}(q)\right]+a \\
& \left.+\mathrm{o}_{(} c_{0}(q)+\mathrm{O}\left[\mathrm{o}^{-1}\right]\right\}(u-q) \\
& +o ́\left(\frac{1}{2} c_{0}^{\prime}(q)+\mathrm{O}\left[\hat{o}^{-1}\right]\right)(u-q)^{2}
\end{aligned}
$$

Combining equation (10) in Section 3 and the equations (15), (16) and (17), the elasticities of substitution can be written as: $:^{34}$

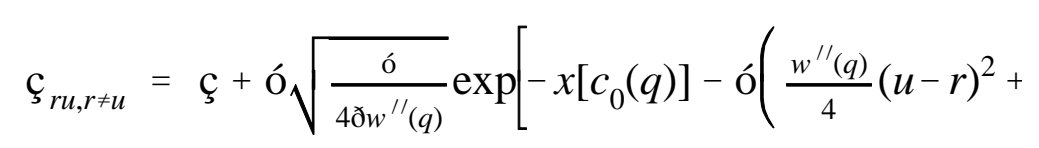

It remains to be shown that $x\left[c_{0}(s)\right]$ converges to $e(s)+w(s)-\ln \left[w^{\prime \prime}(s)\right]-x-p_{x}$ when ó tends to $\infty$. An approximation of the integral in equation (2), using equation (4) to obtain expressions for $f_{s}(s, c)$ and $f_{s s}(s, c)$, yields:

$y(c)=s_{0}(c) c+f\left[s_{0}(c), c\right]-1 / 2 \ln \left[2\right.$ ð ó $\left.w^{\prime \prime}(s)\right]+\mathrm{O}\left[\hat{o}^{-1}\right]$.

Similarly, an approximation of the integral of the definition of $e(s)$ yields:

$e(s)=f\left[s, c_{0}(s)\right]-1 / 2 \ln [2$ ð ó/w" $(s)]+\mathrm{O}\left[o^{-1}\right]$.

Using $s_{0}\left[c_{0}(s)\right]=s+\mathrm{O}\left[\hat{o}^{-1}\right], p(c)=-s_{0}(c) c+w\left[s_{0}(c)\right]+\mathrm{O}\left[\hat{o}^{-1 / 2}\right]$, and

$x(c)=y(c)+p(c)-x-p_{x}$, we have:

$x\left[c_{0}(s)\right]=e(s)+w(s)-\ln \left[w^{\prime \prime}(s)\right]-x-p_{x}+\mathrm{O}\left[\hat{o}^{-1 / 2}\right]$.

Q.E.D.

\footnotetext{
${ }^{34}$ The first-order effect of equation (17) drops out because: $(u-q)=-(r-q)$.
} 
Appendix 2 The inverse of the bordered Hessian matrix

Let $\mathbf{H}$ denote matrix with elements $\left\{c_{i j}\right\}$ as defined by equation (12) for $i \neq j$. Let $\underline{\mathrm{v}}$ denote the vector with value shares $\left\{v_{i}\right\}$. The diagonal elements of $\mathbf{H}$ can be solved from: $\mathbf{H} \underline{\mathbf{v}}=$ $\underline{0}$, where $\underline{0}$ is a vector of zeros. Define:

$\mathbf{H}^{+} \equiv\left[\mathbf{H}, \underline{1} ; \underline{1}^{\prime}, 0\right]$,

$\mathbf{H}^{*} \equiv \mathbf{V}^{+} \mathbf{H}^{+} \mathbf{V}^{+}$,

where $\mathbf{V}^{+}$is a diagonal matrix with: DIAG $\left[\mathbf{V}^{+}\right] \equiv[\underline{\mathrm{v}} ; 1]$. The matrix of elasticities of complementarity $\mathbf{G}$ with elements $\left\{g_{i j}\right\}$ follows from dropping the last column and row of $\left[\mathbf{H}^{*}\right]^{-1} \cdot 35$

Under the assumptions: i) ç $=0$ and: ii) $v_{i}=I^{-1}$, the elements $c_{i j}, i \neq j$, of $\mathbf{H}$ depend on the distance between $i$ and $j$ only. We can therefore define:

$h_{i} \equiv \mathrm{c}_{j, j-i}=1 / 2 \emptyset$ ó 、ó/ð) $\exp \left[-1 / 4\right.$ ó $\left.\emptyset^{2}(i / I)^{2}\right], i \geq 1$.

The value of $h_{i}$ declines rapidly with the value of $i$. Let: $J \equiv \operatorname{int}[2 k I /(\varnothing$ ó) ] where $k$ is, for example, 4; we assume: $J<<I$. Then, $h_{i}$ for $i>J$ is close to zero relative to $h_{1}{ }^{36}$ In the subsequent argument, we will therefore assume $h_{i}=0$ for $i>J$.

Hence, for the case that $J=2, \mathbf{H}^{*}$ satisfies:

${ }^{35}$ Using the notation applied in Section 4.1 and footnote 8, we have: $\mathbf{C}_{\mathrm{PP}^{\prime}}=C^{-1} \mathbf{C}_{\mathrm{P}} \mathbf{H} \mathbf{C}_{\mathrm{P}}$. Hence, the bordered Hessian matrix is:

$\left[\mathbf{C}_{\mathrm{PP}} \underline{\mathrm{C}}_{\mathrm{P}} ; \underline{\mathrm{C}}_{\mathrm{P}}{ }^{\prime} 0\right]=C^{-1} \mathbf{C}_{\mathrm{P}}{ }^{+} \mathbf{H}^{+} \mathbf{C}_{\mathrm{P}}^{+}$, where: $\mathbf{C}_{\mathrm{P}}{ }^{+}=\left[\mathbf{C}_{\mathrm{P}} \underline{0} ; \underline{0} \underline{0}^{\prime} 1\right]$. Inverting the bordered Hessian and pre- and postmultiplying by $\mathbf{F}^{+-1}$, where $\mathbf{F}^{+}$is a diagonal matrix with DIAG $\left[\mathbf{F}^{+}\right]=\left[\underline{\mathrm{F}}_{\mathrm{X}} ; 1\right]$ yields the elasticities of complementarity. $C^{-1} \mathbf{C}_{\mathrm{P}}{ }^{+} \mathbf{F}_{\mathrm{X}}{ }^{+}=\mathbf{V}^{+}$, because $\underline{\mathrm{C}}_{\mathrm{P}}=\underline{\mathrm{X}}$ and $\underline{\mathrm{F}}_{\mathrm{X}}=\underline{\mathrm{P}}$.

${ }^{36}$ An element of $\mathbf{H}^{+}$being close to zero means here that terms in the determinant or co-factors of $\mathbf{H}^{+}$that include at least one of these elements can be ignored relative to the value of the determinant of the co-factor. Due to the definition of $J, h_{i}, i>J$ are smaller than $\exp \left[-k^{2}\right]$, while $h_{1}$ is of the order of unity. By setting $k$ at a higher value the precision can refined without affecting the derivation presented below. 


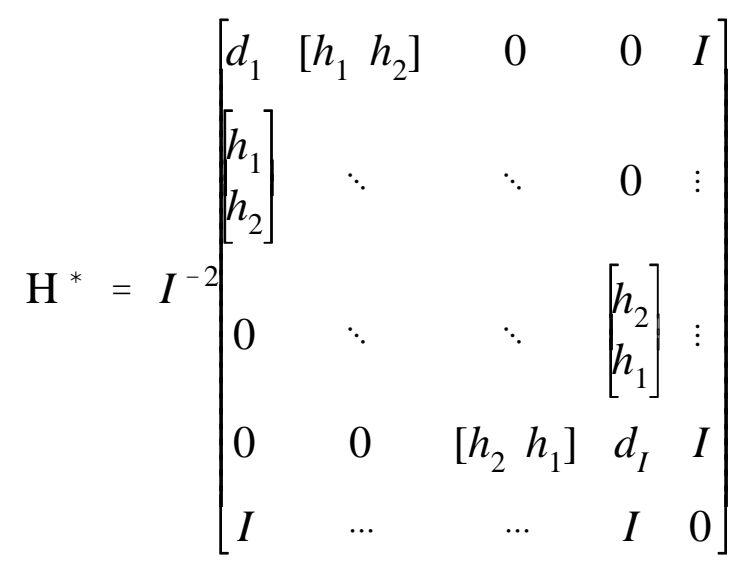

where the diagonal elements $d_{i}$ are given by: $d_{i}=-\hat{O}_{j, j i} c_{i j}$ (since: $\left.\mathbf{H} \underline{\mathbf{v}}=\underline{0}\right)$. Let $\underline{\mathrm{h}}_{j}$ and $\mathbf{g}_{j}$ denote the $j$-th column of $\mathbf{H}^{*}$ and $\mathbf{G}$ respectively. Define the following difference operators with respect to the elements of $\mathrm{g}_{j}$ :

$\ddot{\mathrm{A}} g_{i j} \equiv g_{i+1, j}-g_{i j}$;

$\ddot{\mathrm{A}}^{2} g_{i j} \equiv g_{i+1, j}-2 g_{i j}-g_{i-1, j}=\ddot{\mathrm{A}} g_{i j}-\ddot{\mathrm{A}} g_{i-1, j}$.

The inversion of $\mathbf{H}^{*}$ yields the following equalities for every $j, J<j \leq I-J:^{37}$

i) from the equation $\underline{\underline{h}}_{I+1}{ }^{\prime} \mathrm{g}_{j}=0$ :

$\hat{\mathrm{O}}_{i=1}^{I} g_{i j}=0$;

ii) for every $i, J<i \leq I-J$ and $i \neq j$, from the equation $\underline{\mathrm{h}}_{i} \mathrm{~g}_{j}=0$ :

$æ_{1} \ddot{A}^{2} g_{i j}+O_{m=1}^{J-1} æ_{m+1}\left(\ddot{\mathrm{A}}^{2} g_{i+m, j}+\ddot{A}^{2} g_{i-m, j}\right)=-I$,

where:

$æ_{m} \equiv \dot{O}_{n=m}{ }^{J}(n+1-m) h_{n} \cdot 38$

iii) from the equation $\underline{\underline{h}}_{j}^{\prime} \mathrm{g}_{j}=1$ :

$æ_{1} \ddot{A}^{2} g_{j j}+O_{m=1}^{J-1} \mathfrak{x}_{m+1}\left(\ddot{\mathrm{A}}^{2} g_{j+m, j}+\ddot{\mathrm{A}}^{2} g_{j-m, j}\right)=I^{2}-I$.

iv) for every $i, i \leq J$, from the equation $\underline{\mathrm{h}}_{i}^{\prime} \mathrm{g}_{j}=0$ :

$\grave{\mathrm{e}}_{1 i} \ddot{\mathrm{A}}^{2} g_{i j}+\mathrm{O}_{m=1}^{i-1} \grave{\mathrm{e}}_{m+1, i}\left(\ddot{\mathrm{A}}^{2} g_{i+m, j}+\ddot{\mathrm{A}}^{2} g_{i-m, j}\right)+\mathrm{O}_{m=i}^{J} \hat{\mathrm{i}}_{m} \ddot{\mathrm{A}} g_{i+m-1, j}=-I$,

${ }^{37}$ Similar equations are available for $1 \leq j \leq J$ and $I-J<j \leq I$. They are omitted for convenience.

${ }^{38}$ The above equation follows from rearranging terms in:

$\mathrm{O}_{m=1}^{J} h_{m}\left(g_{i-m, j}-2 g_{i j}+g_{i+m, j}\right)=-I$. 
where:

$\grave{\mathrm{e}}_{m i} \equiv \mathrm{O}_{n=m}{ }^{i-1}(n+1-m) h_{n}$ (hence: $\left.æ_{m}=\grave{\mathrm{e}}_{m, J+1}\right)$,

$\hat{\mathbf{1}}_{m} \equiv \mathrm{O}_{n=1}{ }^{J} h_{n}{ }^{39}$

and mutatis mutandis the same for $i>I-J$;

Consider the case of $J=1$. In that case: $x_{1}=\hat{1}_{1}=h_{1}$. Equality ii) is a second order difference equation of the form: $\ddot{\mathrm{A}}^{2} g_{i j}=-I / h_{1}$.

The value of this second difference is independent of $i$. The elements of $g_{j}$ are therefore points on a parabola. Equality iii) gives the value of the second differential on the main diagonal. Equality iv) establishes the initial condition for the first differential of $\mathbf{g}_{j}$ for $i$ $=1$. Hence, the first differentials of $\mathrm{g}_{j}$ are described by:

$\ddot{\mathrm{A}} g_{i j}=-\left(I / h_{1}\right) i+\left(I^{2} / h_{1}\right) I N D_{i z j}$,

where $I N D_{x}$ is an indicator function being unity if $x$ is true and zero otherwise.

$\ddot{\mathrm{A}} g_{1 j}=-\ddot{\mathrm{A}} g_{I-1, j}=-I / h_{1}$, as is required by equality iv). Integrating this differential equation yields the trajectory of the elements of $\mathrm{g}_{j}$, where equality i) provides the initial condition. Hence:

\section{Lemma 1:}

For $J=1$ :

$g_{i j}=1 / 2\left(I / h_{1}\right)\left(i-i^{2}\right)+\left(I^{2} / h_{1}\right) \operatorname{IND}_{i>j}(i-j)+1 / 2\left(I / h_{1}\right)[(I+1)(I-1) / 3+(I-j)(I-j+1)]$.

The trajectory of $g_{i j}$ is defined by the following characteristics:

i) $\quad \mathrm{O}_{i=1}^{I} g_{i j}=0$;

ii) $\quad \ddot{\mathrm{A}}^{2} g_{i j}=-I / h_{1}$ for $i \neq j$;

iii) $\quad \ddot{\mathrm{A}} g_{1 j}-\ddot{\mathrm{A}} g_{I-1, j}=-2 J I / h_{1}$;

iv) $\quad \ddot{\mathrm{A}} g_{1 j}+\ddot{\mathrm{A}} g_{I-1, j}=0$;

\footnotetext{
${ }^{39}$ This equation follows from rearranging:

$\mathrm{O}_{m=1}{ }^{i-1} h_{m}\left(g_{m j^{-}} g_{i j}\right)+\mathrm{O}_{m=1}{ }^{J} h_{m}\left(g_{i+m, j^{-}} g_{i j}\right)=-I$.
} 


\section{Lemma 2:}

Consider the more general case of $J>1$. Let: $I \rightarrow \infty$ and let: ó $\rightarrow \infty$, such that: $I / \sim$ ó $\rightarrow \infty$. Define: $\mathrm{f}_{i j} \equiv\left[\ddot{\mathrm{A}} g_{i-J+1, j} ; \ddot{\mathrm{A}} g_{i-J+2, j} ; \ldots ; \ddot{\mathrm{A}} g_{i+J-1, j}\right]$, and $\underline{\mathrm{u}}$ as a vector of dimension $2 J-1$ with all elements being semi-positive. Hence: $\ddot{A} \tilde{a}_{i j}=[\underline{u} ' \underline{1}]^{-1} \underline{\underline{u}}{ }^{\prime} \underline{A}_{i j}$ defines a class of moving averages of $\ddot{A} g_{i j}$. Then, characteristic i) is satisfied for $g_{i j}$ and the characteristics ii) till iv) are satisfied in the limit each by at least one moving average of the class $\ddot{A} \tilde{a}_{i j}$, where $h_{1}=$ $I^{3} / \phi^{2}$.

\section{Proof:}

Characteristic i) follows from equality i).

Characteristic ii) follows from writing equality ii) as:

$\underline{\mathrm{d}}\left[\mathrm{f}_{i j}-\underline{\mathrm{f}}_{i-1, j}\right]=-I$,

where $2 i s$ a vector of dimension $2 J-1$ with the coefficients $æ_{m}$ in the appropriate rows.

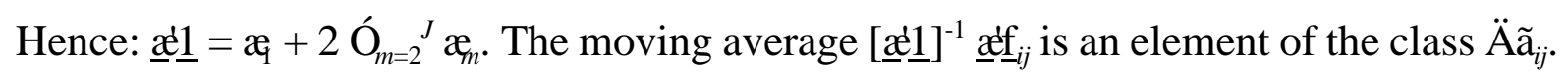
Hence: $\ddot{A}^{2} \widetilde{a}_{i j}=I /[\dddot{a} 1]$. We have:

$$
\begin{aligned}
& \lim _{I \rightarrow \infty} \underline{\mathfrak{\alpha}} \underline{1}=\lim _{I \rightarrow \infty} \sum_{m=1}^{J} m^{2} h_{m}=\lim _{I \rightarrow \infty} \sum_{m=1}^{J} \frac{\phi \hat{\sigma}^{3 / 2}}{\sqrt{4 \hat{\delta}}} m^{2} \exp \left[-\frac{\sigma \phi^{2}}{4} \frac{m}{I}\right. \\
& \int_{0}^{\infty} \frac{I^{3}}{\phi^{2}} x^{2} \ddot{\mathrm{o}}(x) \mathrm{d} x=\frac{I^{3}}{\phi^{2}}
\end{aligned}
$$

where $\varphi($.$) is the density function of the standard normal distribution. The first step$ follows from the definition of $æ_{m}$, the second step from the definition of $h_{m}$. The third step is allowed because: $J \rightarrow \infty$ by the assumption: $I / \wedge 0 \rightarrow \infty$. A transform of variable is applied: $x=(\varnothing / I)$ v(ó/2) $m$. Hence: $h_{1}=I^{3} / \varnothing^{2}$.

Characteristic iii) follows from taking the sum of $\ddot{A}^{2} \widetilde{a}_{i j}$ as defined for characteristic ii) from $i=J+1$ to $I-J$ (using equality iii) for $\ddot{A}^{2} \tilde{\mathrm{a}}_{j j}$ ) yields:

$\ddot{A} \tilde{a}_{J j}-\ddot{A} \tilde{a}_{I J J j}=-2 \emptyset^{2} J / I^{2}$.

Characteristic iv) follows from considering equality iv) for $i=1$ and $i=I$. These equations can be written in vector notation as: $\underline{\hat{1}}^{\prime} \underline{\mathrm{f}}_{J j}=-I$ and $\underline{\hat{1}}^{*} \underline{\underline{f}}_{I J J_{j}}=I$. 
where $\underline{\hat{1}}$ is a vector of dimension $2 J-1$ with elements $æ_{m}$ and zero on the appropriate rows and where $\underline{\hat{1}}^{*}$ is equal to $\underline{\hat{1}}$, but with the elements in the opposite order. Summing both equations yields: $\underline{\hat{1}}^{\prime} \underline{\mathbf{f}}^{*}{ }_{1 j}+\underline{\hat{1}}^{*} \underline{\underline{f}}_{I-J, j}^{*}=0$. Both $\left[\underline{\hat{1}} \underline{1}^{-1} \underline{\hat{1}}^{\prime} \underline{\mathbf{f}}^{*}{ }_{1 j}\right.$ and $\left[\underline{\hat{1}} \underline{1}^{-1} \underline{\hat{1}}^{*^{\prime}} \underline{\mathrm{f}}_{I-J, j}^{*}\right.$ are moving averages of the type mentioned in Lemma 2.

Q.E.D.

Lemma 1 and 2 are the basis for the Conjecture in Section 4. Note that the moving average $\ddot{\mathrm{A}} \tilde{\mathrm{a}}_{i j}$ converges to $\ddot{\mathrm{A}} g_{i j}$ relative to the domain for which $\ddot{\mathrm{A}} g_{i j}$ is defined $(i=1, I-1)$ because $J / I \rightarrow 0$. The reason for stating Conjecture 1 as a conjecture and not as proposition is that the above proofs show that a moving average $\ddot{A} \tilde{a}_{i j}$ follows the trajectory described in Lemma 1, but that the proofs do not rule out the possibility that $\ddot{A} g_{i+m, j}$ might cycle around the trajectory in the range $m=-J+1, J-1$ covered by the moving average $\ddot{A} \tilde{a}_{i j}$. Numerical calculations show that there is indeed some cycling at boundaries of the matrix $(i \approx J, i \approx I-J)$ and at the main diagonal. However, for large $I$, the trajectory converges quickly towards that in Lemma 1 outside these areas. 
Appendix 3 The classification of occupations

The classification of occupations into 30 groups is based upon the three-digit codes available on the CPS tapes. Four criteria guided the construction of the classification:

1) in the aggregation of three-digit codes into 30 groups, the two-digit classification of 43 groups available on the CPS tapes must be followed as closely as possible;

2) the differences in the mean hourly wage rate within a group must be small;

3) the codes before 1980 (1973 and 1979) differ from those after that date (1985 and 1990): the classification for the latter two years has to be replicable for the former two years and vice versa (Bureau of the Census, 1989);

4) groups may not be too small.

For the occupations in manufacturing, criterion 1) conflicts strongly with criterion 2). There, the only workable solution was to give criterion 2) preference. Applying these criteria yielded the following classification: 
Coding of occupational groups of CPS codes

\begin{tabular}{|c|c|c|c|}
\hline group & $\underline{\text { description }}$ & $\underline{1970 \text { codes }}$ & $\underline{1980 \text { codes }}$ \\
\hline 1 & public servants & 201,222 & $3-6$ \\
\hline 2 & managers \& related & $\begin{array}{l}\text { 1,56,202-3,205,210-3, } \\
215-6,224-5,231,233 \\
235,240,452\end{array}$ & $7-18,23-37$ \\
\hline 3 & managers n.e.c. & $195,220,223,230,245$ & 19,243 \\
\hline 4 & specialists, lawyers & $\begin{array}{l}2,4-6,10-5,20-1,23,30- \\
1,34-6,55,164,704,931\end{array}$ & $43-68,178-9,227$ \\
\hline 5 & scientists, teachers & $\begin{array}{l}3,25,42-5,51-4,64,75-6 \\
81,102-5,110-6,120-6 \\
130-5,140,153,155,172 \\
923\end{array}$ & $\begin{array}{l}69-83,95-6,98-154 \\
204,213,215,229,233\end{array}$ \\
\hline 6 & med.specialists, pilots & $61-3,65,71-3,163,170$ & $84-6,226$ \\
\hline 7 & non-secondary teachers & $\begin{array}{l}24,26,32,33,74,141-2 \\
144-5,174,181-5,190-2\end{array}$ & $97,156-65$ \\
\hline 8 & recreation, entertaining & $86,91-6,100,175,194,425$ & $166-74,176,180-97$ \\
\hline 9 & technicians & $\begin{array}{l}80,82-3,85,150-2,154, \\
156,161-2,165,171,173, \\
325,926\end{array}$ & $\begin{array}{l}203,205-12,214,216-25, \\
228,234-5,363,366\end{array}$ \\
\hline 10 & sales representatives & $\begin{array}{l}22,260,265,270-1,281-2 \\
363\end{array}$ & $253-9$ \\
\hline 11 & sales workers & $\begin{array}{l}261-2,264,266,283-5,310 \\
314\end{array}$ & $260-85$ \\
\hline 12 & supervisors admin. & 312 & $300-7$ \\
\hline 13 & computer operators & 343,350 & $308-9$ \\
\hline 14 & typist & $320,330,364,391$ & $315-7,319-23$ \\
\hline 15 & secretaries & $370-2,376,390$ & $313-4,318$ \\
\hline 16 & clerks & $\begin{array}{l}301,303,305,311,313, \\
315,321,323,326,332-4, \\
341-2,344-5,355,360,362, \\
374-5,381-2,384-5,392, \\
394-5\end{array}$ & $325-8,336-53,356-89$ \\
\hline 17 & postal service workers & 331,361 & $354-5$ \\
\hline 18 & private household, food & $910-4,916,981-4$ & $400-5,407,430-4,436-44$ \\
\hline 19 & child care workers & 980 & 406 \\
\hline 20 & waiters & 915 & 435 \\
\hline
\end{tabular}


21 protective services

961,963-5

410-24

22

guards, packers

960,962

425-7

23 other medical \& related

84,921-2,943

445-6,448,454-5

24 nurse aid, maids

$90,101,143,180,193,901-$ 3,924-5,932-5,940-2,9445,950,952-4

25

agricultural workers

$740,752,755,761,801-2$, $806,821-4$

$155,175,177,198-9,447$, 449-53,456-64,466-9

26

specialized manufac.

$226,433,455-6,471,514$, $525,550,552,554,710$

508,527-43,553-5,557,577, $597,645,656,695,699,823-4$, 826,845

27 skilled manufac.

221,403-4,410,412,415, 421,424,430-1,436,441, 445-6,453,461,470,4745,481-6,491-2,495,502, 515-6,520-2,530-1,533, 535,545,560-2,571,601, 603,614-5,626,640,642, $680,701,712-3$

28 medium manufac.

405,411,413,416,420, $426,435,440,442,454$, $462,472-3,480,503-5,510-$ 2,523,534,536,540,546, 602,610,620-1,635,641, 644,650-3,656,660-1,681, 690,692,694-5,703,706, 715,750-1,753-4,763

$29 \quad$ low-skilled manufac.

401-2,422-3,434,443-4, $450,501,506,542-3,551$, $563,604-5,612-3,622,624-$ 5,631,633-4,636,643,645, 662,665-6,670-4,705, $714,760,770,780,785$

503,507,515-6,518-26,533-9, 544-9,556,558-63,565,567,573, 575,584-5,588-94,596,598,613$37,643-44,653,655,676,689-$ 94,696,707,714-5,724,734-5, $757,783,797,803,825,828,833-$ $44,849-55,867$

505,509-14,517,564,566,569, 576,579-83,587,595,599,639, 646-9,654,657,675,678-9,684, 703-6,708-13,717-23,736,755-6, 758-9,777-9,785,787,796,804, $808,829,848,856-9,869,875,883$

658-74,677,683,686-8,725-33, 737-43,749-54,763-74,784,786, 789-95,798-9,805-6,809,814, 863-6,873,876,878,888-9

unskilled manufac.

611,623,630,663-4,711, 762,764 
Table 2 The value of $j$, and $C\left(j_{i t}\right)$ for occupational groups

\begin{tabular}{lll} 
waiters & 0.000 & -9.596 \\
unskilled manufac. & 0.065 & -7.123 \\
typist & 0.124 & -5.121 \\
private household, food & 0.130 & -4.058 \\
nurse aid, maids & 0.166 & -3.326 \\
agricultural workers & 0.172 & -2.707 \\
sales workers & 0.179 & -2.566 \\
medium manufac. & 0.216 & -1.910 \\
guards, packers & 0.219 & -1.609 \\
other medical \& related & 0.241 & -0.973 \\
low-skilled manufac. & 0.242 & -0.882 \\
secretaries & 0.270 & 0.377 \\
non-secondary teachers & 0.314 & 0.680 \\
clerks & 0.347 & 1.573 \\
postal service workers & 0.354 & 1.573 \\
skilled manufac. & 0.412 & 2.792 \\
child care workers & 0.442 & 3.375 \\
technicians & 0.452 & 3.701 \\
specialized manufac. & 0.462 & 4.016 \\
protective services & 0.484 & 4.033 \\
managers \& related & 0.532 & 4.691 \\
sales representatives & 0.542 & 4.869 \\
med.specialists, pilots & 0.607 & 5.617 \\
managers n.e.c. & 0.611 & 5.771 \\
computer operators & 0.645 & 6.236 \\
supervisors admin. & 0.656 & 6.241 \\
scientists, teachers & 0.669 & 6.443 \\
public servants & 0.717 & 6.976 \\
recreation, entertaining & 0.735 & 7.126 \\
specialists, lawyers & 1.000 & 10.814 \\
\hline
\end{tabular}


Table 5 The effect unemployment, truncation and compression component of increasing the minim wage in the south

\begin{tabular}{llllllllll}
\hline $\begin{array}{l}\text { increase } \\
\text { minimum } \\
\text { wage }(\%)\end{array}$ & 1979 & \multicolumn{1}{c}{1985} & \multicolumn{7}{c}{1990} \\
\cline { 2 - 10 } 5 & 1.4 & 0.7 & 4.3 & 0.9 & 0.8 & 4.2 & 0.4 & 1.8 & 3.2 \\
10 & 3.0 & 1.4 & 8.6 & 1.9 & 1.8 & 8.2 & 0.8 & 3.7 & 6.3 \\
20 & 5.9 & 3.0 & 17.0 & 3.8 & 3.7 & 16.3 & 1.9 & 8.5 & 11.5 \\
\hline $1:$ & employment loss (\%) & & & & & & \\
$2:$ & truncation component in wages (\%) \\
$3:$ & compression component in wages $(\%)$
\end{tabular}


Figure 1 Wage function and skill type choice for a $c$ type firm
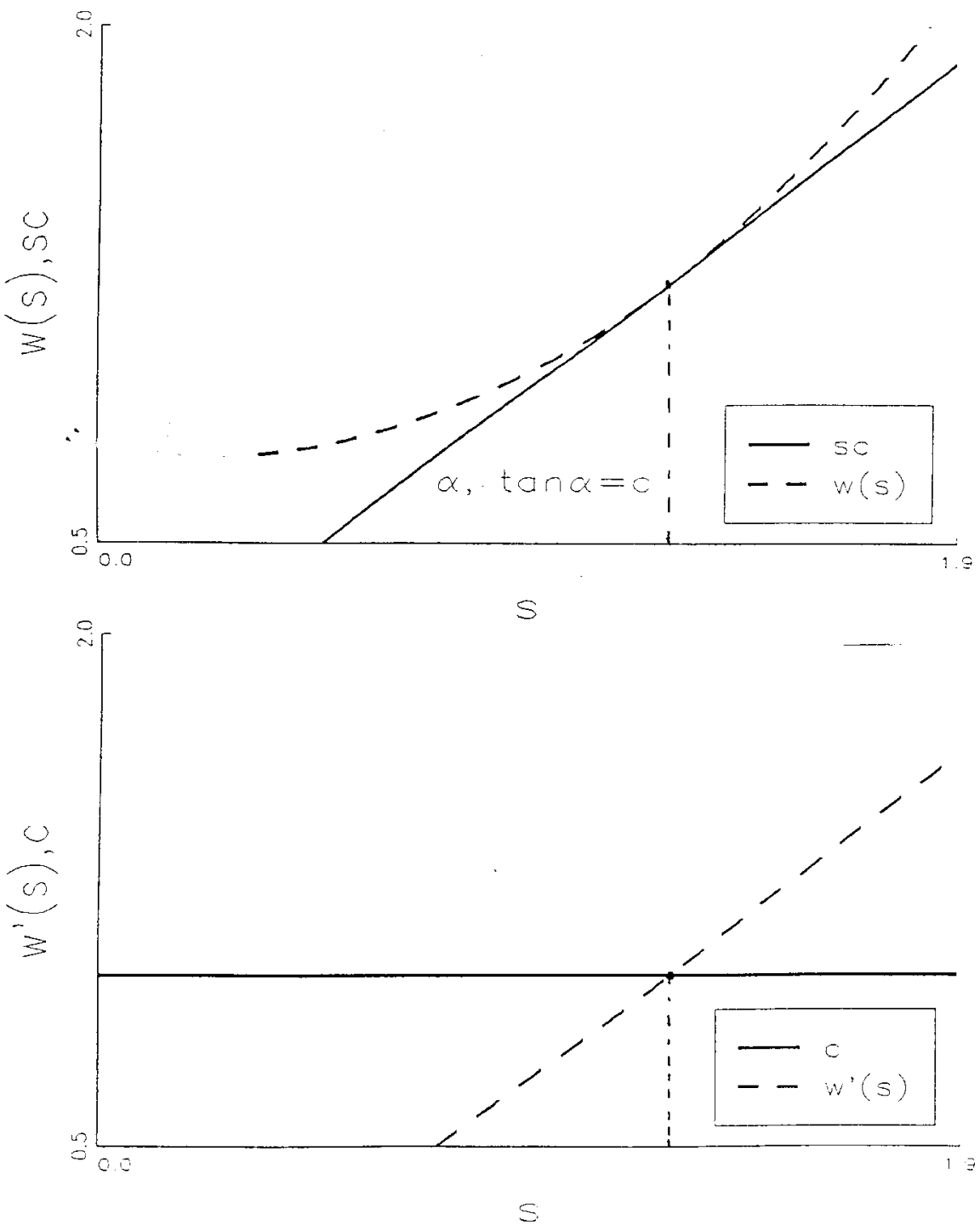
Figure 2 Elasticities of complementarity for various $j / I$

Legenda:

: $j / I=0.0$

$\longrightarrow: j / I=0.5$

$: j / I=1.0$

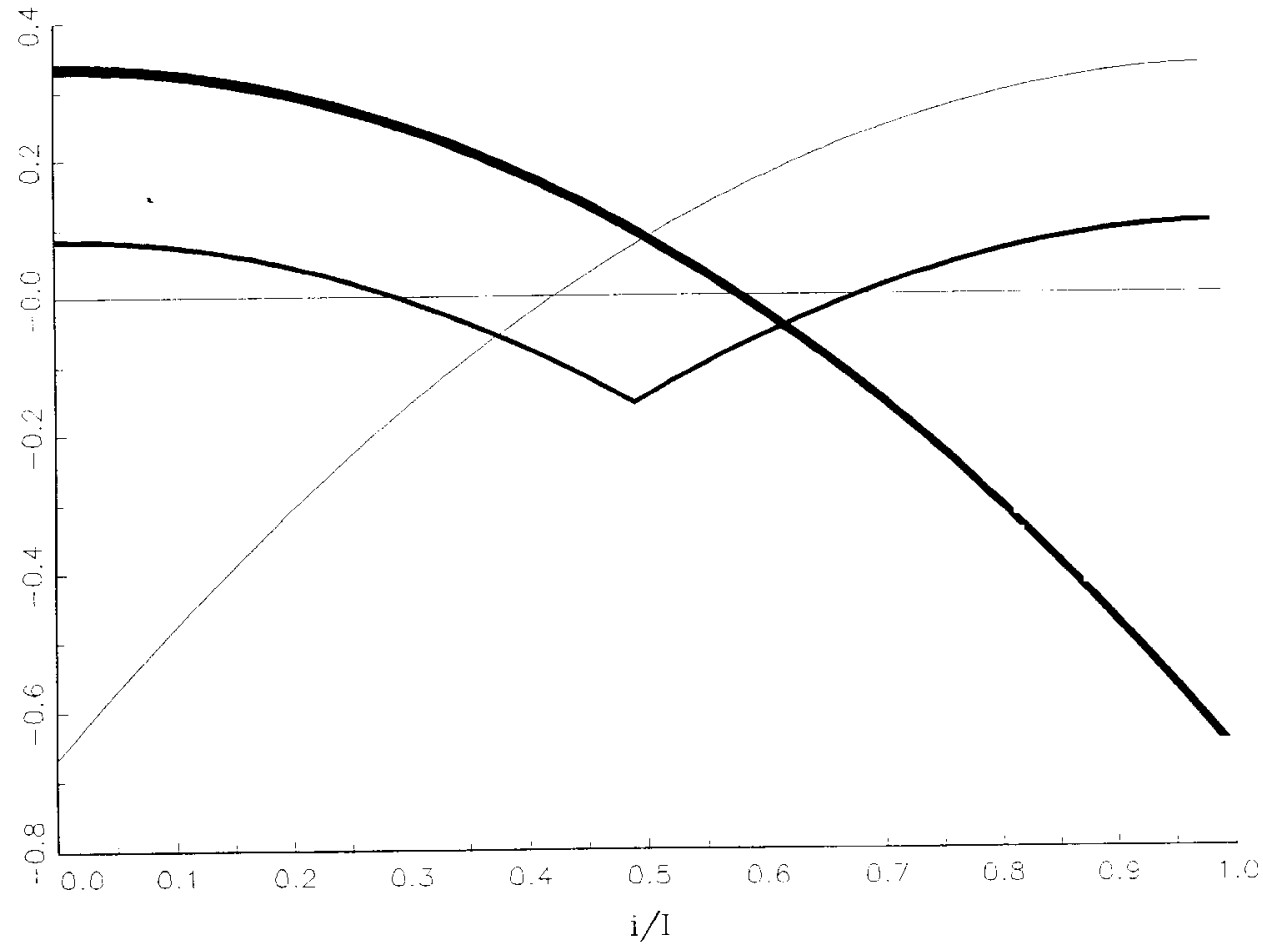


Figure 3 The return to the skill index, $W_{t}^{\prime}(q)$, by the log wage level by region for all years in the sample
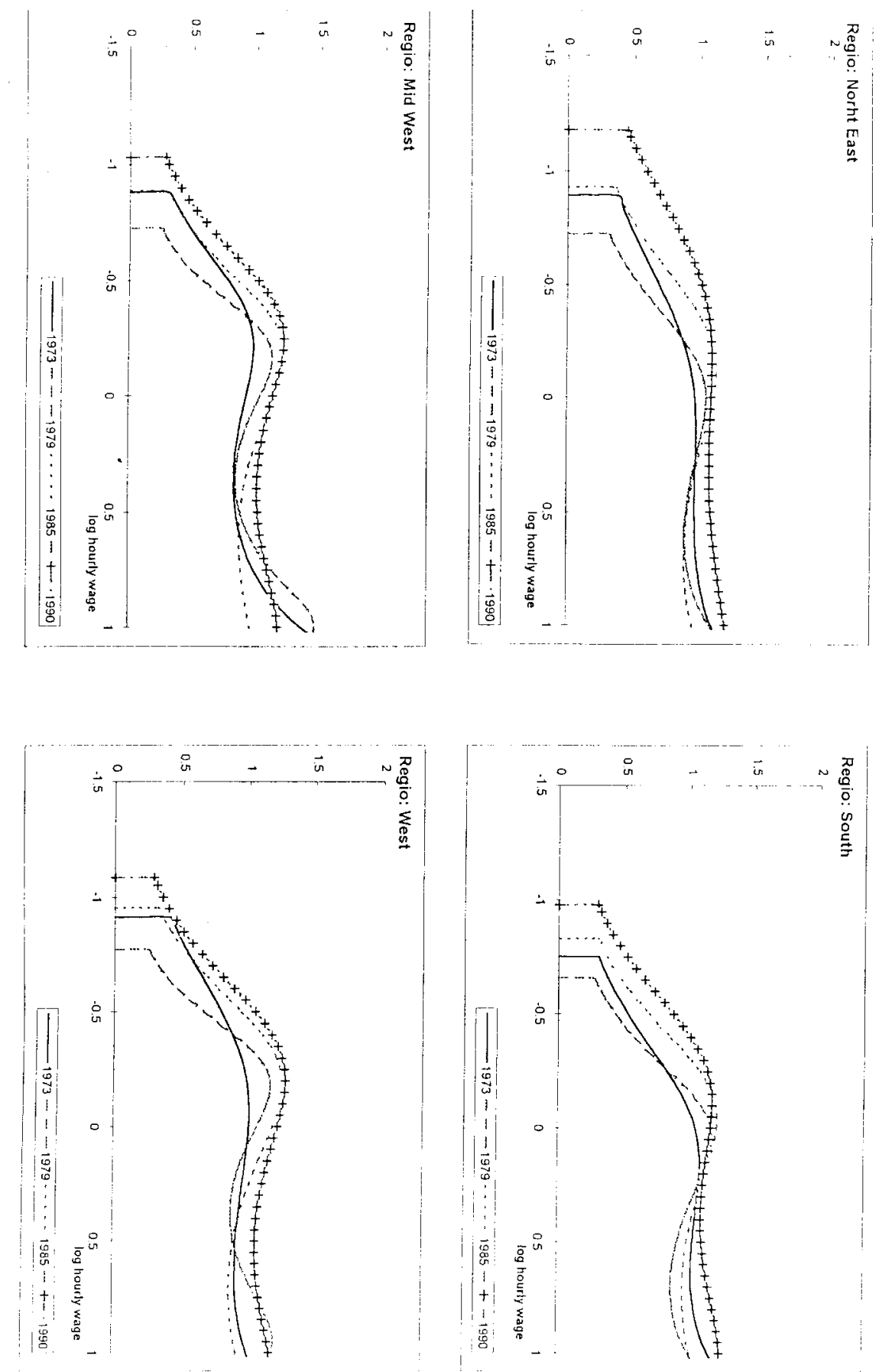
Figure 4 Wage function before, $w 1(s)$, and after, $w 2(s)$, the minimum wage increase

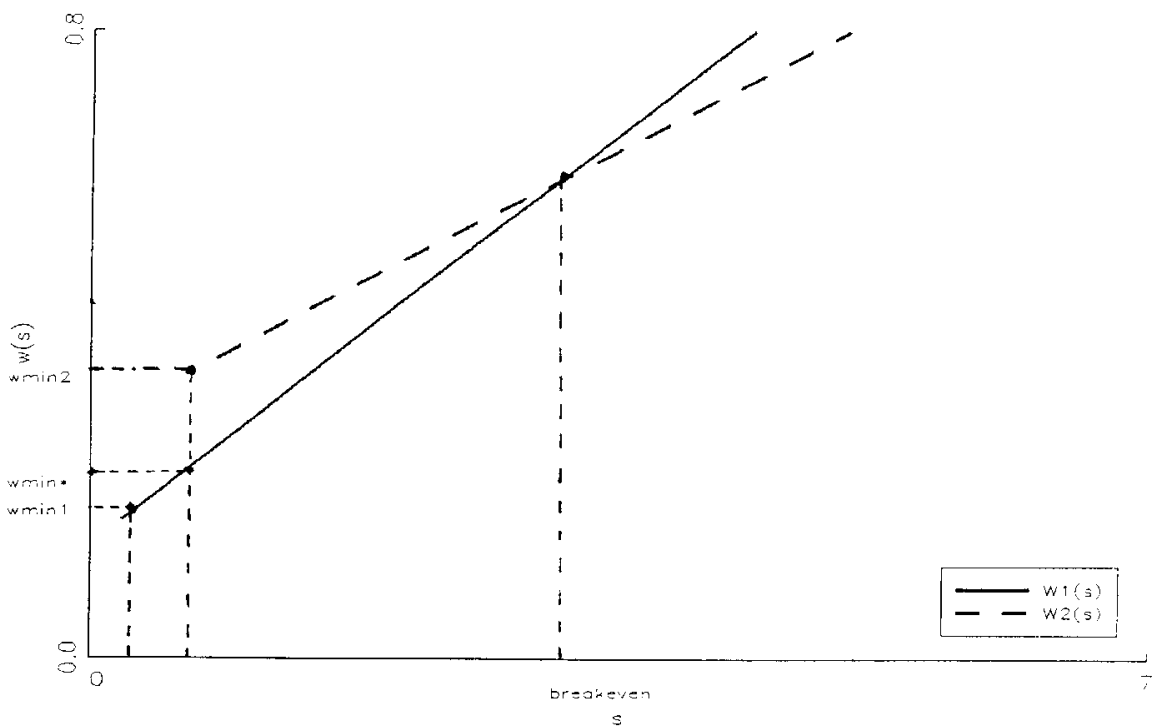


Figure 5 The wage and skill distribution in the south for 1979,1990 , and 1990 with the 1979 minimum wage

Legenda:

: 1979

궁 : 1990

: 1990, minimum wage 1979

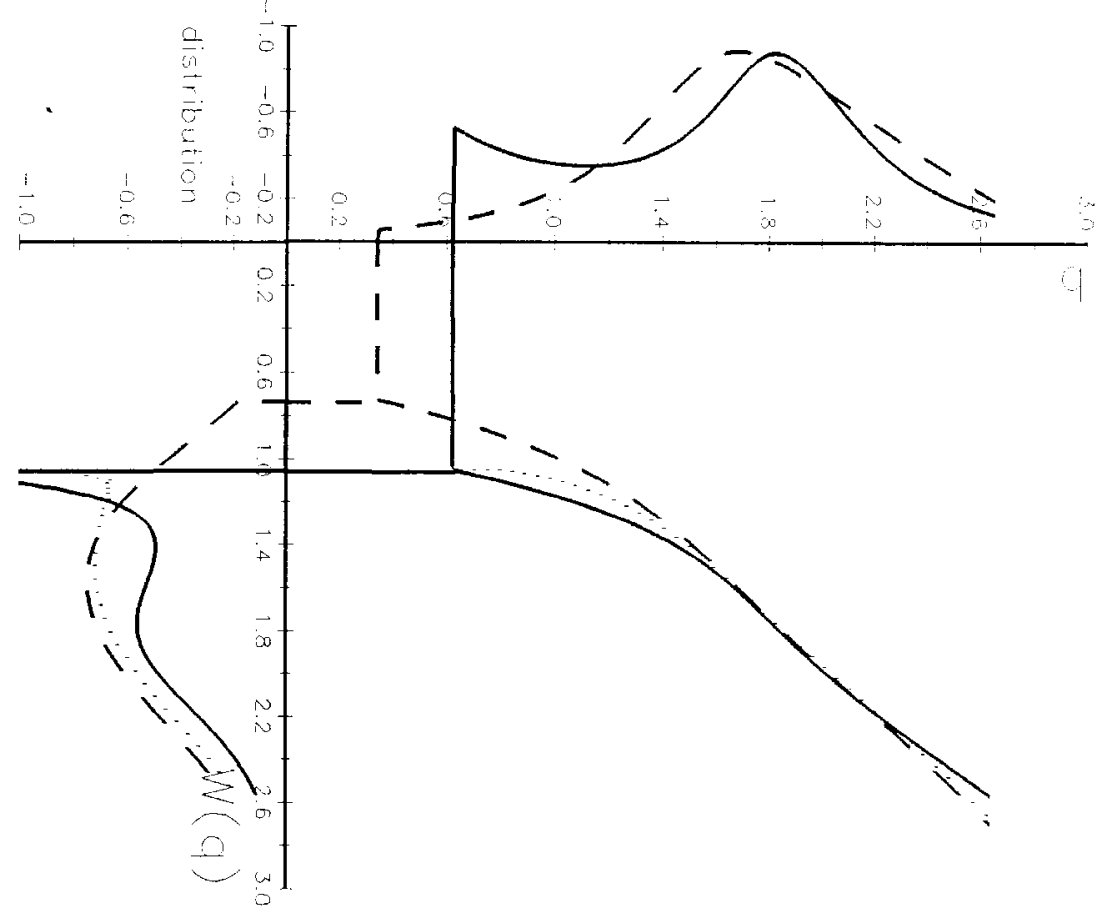

